\title{
Paleotsunami History of Hachinohe, Northern Japan: A Multiproxy Analysis and Numerical Modeling Approach
}

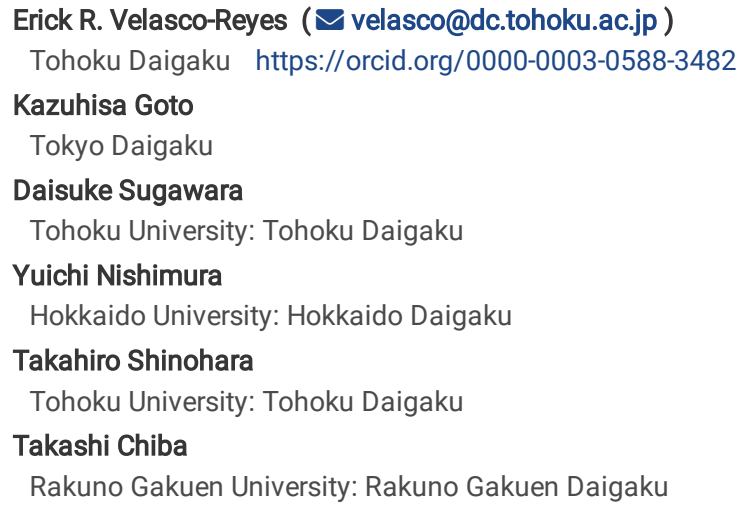

Version of Record: A version of this preprint was published at Progress in Earth and Planetary Science on April 1st, 2022. See the published version at https://doi.org/10.1186/s40645-022-00477-4. 


\begin{abstract}
Paleotsunami studies along the Pacific coast of Tohoku, northern Japan, have been considerably developed recently, particuvclarly after the massive impact of the 2011 Tohoku-oki tsunami. Nevertheless, in the southernmost Shimokita Peninsula, studies pertaining to paleotsunami are underdeveloped, leading to vague understanding of the tsunamigenic sources northward of the Tohoku region, along with incomplete hazard evaluation. Paleotsunami deposits in Shimokita can be related not only to the Japan trench along the Sanriku coast, but also to the Kuril trench along the Pacific coast of Hokkaido. In this study, we unveiled the paleotsunami history of Hachinohe in northern Tohoku. Using a combination of sedimentological, geochemical, paleontological, and mineralogical proxies, we characterized seven sand layers that dated from ca. 2700 to ca. $5500 \mathrm{yr}$ BP based on radiocarbon $\left({ }^{14} \mathrm{C}\right)$ ages as event deposits of marine origin. Sedimentological and paleontological evidence coupled with ground penetrating radar imagery revealed a marsh environment comprising successive extinct ponds, controlling the depositional environment. Numerical modeling ruled out the possibility of storms as genetic sources, leading to the conclusion that the presence of event deposits with marine sediments in the study area would be associated with tsunami inundation episodes. Based on ${ }^{14} \mathrm{C}$ dating, the average frequency of recurrence of tsunamis is estimated as $545-736$ years with a $2 \sigma$ error range. This interval is shorter than that estimated in Harashinai, northern Sanriku Coast, near our survey site, which suggests an average of 530 to 956 years (2б) for the same time frame. The previously recorded limited paleotsunami evidence and absence of an estimated recurrence interval in the Shimokita Peninsula reaffirms the importance of Hachinohe as a tsunami record site for the activity of both trenches.
\end{abstract}

\title{
1 Introduction
}

\subsection{Paleotsunami studies in the Pacific coast of northern Japan}

The Pacific coast of northern Japan is established as one of the regions worldwide with large and frequent earthquakes. Earthquake events occur not only in relation to the Japan Trench, facing the Tohoku region, but also to the Kuril Trench, facing Hokkaido Island (Seno 1978; Ide and Aochi 2013). Historical events demonstrated the remarkable tsunamigenic capacity of the Japan Trench in 869 A.D., 1611, 1896, 1933, 1968, and 2011 (Hatori 1975; Tanioka and Satake 1996; Nagai et al. 2001; Ozawa et al. 2011; Uchida et al. 2016) (Fig. 1a). In the 17th century, a massive tsunami associated with the activity of the Kuril Trench exhibited a high capacity of inundation along the coast of Hokkaido, leaving deposits far inland and in high cliff areas (loki and Tanioka 2016).

The magnitudes of these earthquakes have attracted the attention of scientific community, particularly after the catastrophic 2011 Tohoku-oki tsunami (TOT), which clearly demonstrated that understanding tsunami hazard was not adequate to develop an effective disaster risk reduction strategy and prevent casualties due to tsunami episodes (Goto et al., 2014). To increase the knowledge regarding the frequency and magnitude of events from historical records, several studies evaluating the sedimentological evidence of tsunamis have been conducted along the Sanriku Coast (Inoue et al. 2017; Ishimura and Miyauchi 2015; Ishizawa et al. 2018; Takada et al. 2016) and the Pacific coast of Hokkaido (Nanayama et al. 2002; Nanayama et al. 2003; Hirakawa et al. 2005; Nanayama et al. 2007; Ishizawa et al. 2017).

Regarding geological studies of paleotsunami deposits, clarifying the origin of tsunami, regional stratigraphic correlation, age, and source estimation is still a matter of discussion, not only in Japan but worldwide (Castillo-Aja et al. 2019; Costa et al. 2016; Goto et al. 2012; Ishizawa et al. 2018;Moreira et al. 2017; Ramírez-Herrera et al. 2016; Takada et al. 2016). To the best of our knowledge, the only technique to obtain information regarding the spatial extent of tsunami deposits is consistent survey of coastal areas, with maximum possible resolution. The sedimentological characteristics of the tsunami deposits largely depend on the distribution and composition of sediments in the shore zone and topography on the backshore, thereby varying the geometry and lithology over short distances (Jagodziński et al. 2009; Abe et al. 2012; Moreira et al. 2017). In the northern Pacific coast of Honshu Island, a large gap of 60 km exists without paleotsunami studies, from Misawa in the Shimokita Peninsula (Tanigawa et al. 2014a) up to Hirono Town (Harashinai site), northern Iwate Prefecture (Takada et al. 2016), indicating sparse geological evidence for prehistoric events in the Hachinohe area (Fig. 1e). Opposite to the Sanriku coast, several studies have initiated (e.g. Imaizumi et al. 2010; Goto et al. 2015; Takada et al. 2016; Inoue et al. 2017; Ishimura 2017; Goto et al. 2019) (Fig. 1e). Due to the peculiar location and distance from the two neighboring subduction zones, the southern Shimokita Peninsula helps in not only to recover the data on the maximum northward extent of tsunami events from the Japan Trench, but also to obtain paleotsunami data that can elucidate the seismic activity of the Kuril Trench and the flexion between the two trenches.

\subsection{Objective}

This study contributes toward the understanding of tsunami hazard assessment in northern Japan by identifying, dating, and correlating paleotsunami deposits in Hachinohe. Our methodology was based on the utilization of a combination of sedimentological, geochemical, geophysical, and paleontological tools, along with numerical simulations for inundation and sediment transport.

\subsection{Brief review of approaches for paleotsunami deposit identification}

Previous paleotsunami studies suggest that the characteristics of the sedimentary tsunami evidence are controlled by three essential factors: the morphology of the nearshore, foreshore and backshore; sediment availability; and wave transportation capacity (Albertao et al. 2008; Goto et al. 2014; Kain et al. 2015; Shinozaki et al. 2015b; Watanabe et al. 2017). Thus, the texture and morphology of the deposit reflect the governing physics and boundary conditions related to the nature of the marine origin surge. The characteristics such as upward fining, landward thinning and finning, erosional sedimentary structures, and paleocurrent directions are relevant indicators of the nature of the flow and are key points to link the deposit to a tsunami event (Sugawara et al. 2008). However, in several cases, such characteristics can also be the result of river floods (Inoue et al. 2017; Shyu et al. 2019). By performing grain size analysis, it is possible to infer some of these textural characteristics and contribute toward the understanding of the sedimentary environment, energy, and transport media involved during its deposition (López 2017). In addition, the characterization of the sedimentary fabric can be complemented by identifying the relative density changes generated by lithological variations (Kain et al. 2015). X-ray computed tomography (CT) can illustrate the compositional variations in the

Page 2/28 
sedimentary sequence because it records the attenuation of X-rays on materials due to the Compton scattering effect, the magnitude of which depends primarily on density and consequently on the mineralogy (Mees et al. 2003). For instance, Paris et al. (2019) utilized high-resolution micro X-ray CT to characterize the sedimentary fabric, grading, and imbrication angles, inferring tsunami as the transport agent.

In addition, geochemical characterization of paleotsunami deposits can be performed by determining relative quantities of water-leachable ions, exchangeable cations, salinity, major elements, trace elements, and carbonates (Chagué-Goff et al. 2017). Nonetheless, because of the leaching effect of rainwater and groundwater on high-mobility elements, only major and trace elements must be utilized to characterize deposits with long-term diagenesis, that is, paleotsunami deposits (Goto et al. 2012; Shinozaki et al. 2015a; Chagué-Goff et al. 2017; Judd et al. 2017). In such a case, X-ray fluorescence (XRF) core scanning is an excellent alternative for rapid and effective identification of wide range of elements in a sedimentary sequence, and it has been implemented to identify geochemical signatures related to tsunami deposits (Andrew et al. 2012; Chagué-Goff et al. 2017; Judd et al. 2017; Ishizawa et al. 2019). However, because the characterized group of elements can possess different mineralogical arrangements and hence different geological meanings, it is imperative to reinforce element interpretation with mineralogical identification techniques such as X-ray diffraction (XRD) (Arnaud et al. 2015). Additionally, XRF is beneficial for relative quantification of the organic matter content (Croudace et al. 2006; Chawchai et al. 2016), as demonstrated in previous tsunami deposit studies (Chagué-Goff et al. 2016; Judd et al. 2017). This is achieved by obtaining the ratio between Compton and Rayleigh scattering (inc/coh), which is directly associated with the presence of materials with low atomic mass, thereby enhancing the presence of organic matter-rich sediments (Croudace et al. 2006; Chawchai et al. 2016). The obtained data have been analyzed using multivariate statistical methods, such as principal component analysis (PCA), to find associations or linear dependencies among the measured elements and clarify the sedimentary source (Chagué-Goff et al. 2016). To support geological data, few studies have used diatom analysis, foraminiferal DNA, plant detritus identification, and shell fragment recognition to clarify the terrestrial or marine origin of event deposits (Chagué-Goff et al. 2015; Cisternas et al. 2018; Judd et al. 2017; Sawai et al. 2009; Szczuciński et al. 2016; Tanigawa et al. 2014b).

Furthermore, the differentiation of the origin of the deposit between storms or tsunamis remains an under-debated topic, and the methods utilized for their characterization considerably depend on the unique geological and morphological settings of every survey site (Morton et al. 2007; Sugawara et al. 2008; Goff et al. 2012). Recent studies have demonstrated that numerical modeling is suitable for solving this problem (Inoue et al. 2017; Watanabe et al. 2018). Watanabe et al. (2018) conducted numerical sediment transport simulations to calculate the maximum sand extent due to storm and tsunami surges on the Sendai Plain. The results exhibited that in a low-slope coastal topography, storm surges could inundate further inland than tsunami waves. However, the extent of the deposition of storm is limited to areas close to the beach, owing to flow characteristics. In tsunamis, the sediment transport capacity is typically high and independent of the slope.

\section{Study Area}

The study area is located in the northernmost part of the coastal zone of Hachinohe City, Aomori Prefecture, Japan, surrounded by the Oirase and Gonohe rivers. A succession of uplifted marine terraces, as a result of the constant tectonic uplift related to the subduction in the Japan Trench (Miyauchi et al. 1987; Niwa and Sugai 2021), controls the stepwise morphology of the area. Based on digital elevation models (DEMs), it is possible to infer the presence of the four major terraces (Fig. 1c). The lowest terrace 1 is a $2-3 \mathrm{~m}$ high surface that includes river terraces, backshore deposits, and a poorly developed marine terrace; a $4 \mathrm{~m}$ high uplifted marine terrace 2 is edged by the past lateral migration of the surrounding rivers. A $5 \mathrm{~m}$ high uplifted marine terrace 3 , known as the Shibayama Surface (Miyauchi et al. 1987), contains the survey points (Fig. 1d). A $35 \mathrm{~m}$ high terrace 4 has been named Takadate Surface by Miyauchi et al. (1987).

Land use mostly includes industrial activities and housing on terraces 1 and 2 , paddy fields on terrace 3 , and housing on terrace 4 . The presence of $5 \mathrm{~m}$ high marine-surge protection structures on the beach berm and river dikes is remarkable in the current topography. In the northern part of the $4 \mathrm{~m}$ surface, a jshaped depression is present that can be morphologically related either to a paleo-pond or a cutoff meander (Fig. 1c).

As a first approximation to paleotsunami research in Hachinohe, Velasco et al. (2019) conducted numerical modeling for storm and tsunami surges to compare their advancement. To reproduce natural coastal settings, artificial features, such as protection walls and breakwaters, were removed from the DEM used in this study. Extreme and improbable storm parameters were assumed for the storm simulations. For the tsunami simulation, the source parameters of the 2011 TOT were applied. The results showed that even under the most severe storm conditions, erosion and sedimentation are limited to areas below terrace 2, under the assumption of the present sea level (Fig. 1). In addition, tsunami surges derived from the 2011 TOT can inundate further inland and reach the edge of terrace 3 (Fig. 2, Velasco et al., 2019). In practical terms, this means that up to a height of $3 \mathrm{~m}$, the sedimentary environment can be affected by the occasional occurrence of extreme events such as river floods, storms, and tsunamis. Moreover, in areas higher than $3 \mathrm{~m}$, the sedimentary environment can solely be affected by either tsunamis or river floods, restraining the differentiation of event deposits to a marine or terrestrial origin. As the modeled tsunami surge reached the terrace 3 edge, we selected a survey transect along such a surface (Fig. 2c).

\section{Methods}

\subsection{Ground penetrating radar (GPR) survey and excavation using Handy}

\section{Geoslicer}

As reported by Velasco et al. (2019), who performed a preliminary site survey, GPR lines were used to select the best possible survey points by identifying paleosurfaces with the maximum sediment preservation potential. This study used processed GPR imagery for paleotopographic interpretation.

We used a GPR controller GSSI SIR®-4000 (Geophysical Survey Systems, Inc., USA) with an antenna set up to a frequency of $400 \mathrm{MHz}$ to achieve a maximum effective vertical penetration of $3 \mathrm{~m}$ and a maximum resolution of $18 \mathrm{~cm}$ (1/4 of wavelength). GPR data were processed using the RADAN 7 software by GSSI 
A Handy Geosclicer (Takada et al. 2002) was used for core sampling. Sediment core samples were extracted along a transect perpendicular to the shoreline.

\subsection{Non-destructive core scanning: $X$-ray CT}

X-ray CT was conducted using the scanner Toshiba Aquilion Prime at the Center for Advanced Marine Core Research facilities at Kochi University. Horos software (open source licensed under the GNU Lesser General Public License, Version 3.0 (LGPL 3.0) was used to generate 3D reconstructions, from axialperpendicular slides obtained every $0.5 \mathrm{~mm}$. In addition, we modified the colors depending on the CT units to enhance the visualization of lithological changes. Image $\mathrm{J}$ software (public domain Java image processing and analysis program) extracted a gray value profile from the front-axial images to be included in the log worksheet along with the $\mathrm{X}$-ray fluorescence scanning results.

In the 3D reconstruction, the original grayscale was modified to blue, green, and yellow scales to facilitate the recognition of lithological changes, sedimentary structures, and sediment grading. These colors were manually selected on Horos for convenience to differentiate the lithological changes. Threshold values were determined by first identifying sand, peat, tephra layers, and roots and further manually assigning such values, thereby allowing faster identification of composite materials.

\subsection{Non-destructive core scanning: Magnetic susceptibility}

The magnetic susceptibility (MS) of the sediment core samples was measured using the core logging sensor (Model MS2C, Bartington, USA) with a resolution of $10 \mathrm{~mm}$. The obtained values were plotted as a vertical profile and included in the log worksheet along with the ITRAX profiles. As MS values are absolute quantities, we utilized them for lateral comparison among the measured cores.

\subsection{Non-destructive core scanning: Micro XRF (ITRAX)}

We utilized XRF core-scanning by ITRAX (Löwemark et al. 2019) to obtain the content of the major elements. The equipment was facilitated by the Center for Advanced Marine Core Research at Kochi University. The measurements were conducted using a molybdenum target tube with acquisition parameters of 60 $\mathrm{kV}, 34 \mathrm{~mA}$, exposure time of $200 \mathrm{~ms}$, and step size of $1 \mathrm{~mm}$.

XRF data were further processed to identify points with unreliable measured values due to the irregularities in the sample or misleading measurements (validity profile). Elemental spectra were normalized by the total count rate (kcps) to correct for the effect related to sample quality and measurement parameters (Chagué-Goff et al. 2016). For elements with high-frequency noise, we utilized a high-pass filter by applying the discrete Fourier transform (DFT) with a threshold of five components, as observed in the chlorine and rubidium spectra.

PCA and linear discriminant analysis (LDA) were utilized to identify geochemical changes among the sand layers and their provenance. PCA has been primarily used in tsunami sedimentology to identify relationships or discriminate among sand layers (Trauth 2015; Chagué-Goff et al. 2016). Herein, PCA was applied to identify geochemical changes in the same sediment core. However, LDA was utilized for sand correlation among the core samples. Based on the ITRAX-element detection rates (Bishop 2016) and pattern profiles, we used Sr, Ca, Mn, Ti, Fe, Cr, Ta, Zr, Si, K, Al, and Rb as inputs for the PCA. As our interest lies in the geochemical characterization of the sand layers, we extracted the data corresponding to every sand layer.

LDA and Fischer discriminants are valuable statistical techniques for classification and reducing components when inferring a relationship among them. Such a linear function maximizes the distance between two classes and minimizes the variation between each class (Rao and Govindaraju 2013). Herein, LDA determined the relationships among the sand layers in every core sample. To perform such analysis, we selected ITRAX-element detection rates restricted to the sand layers in every core and compared them using the static technique. In ITRAX, because the quantification of major elements in counts per second (cps) largely depends on the measuring parameters and sample conditions (Chagué-Goff et al. 2016; Löwemark et al. 2019), it is not possible to conduct direct associations of elemental values among different cores, even after kcps normalization. As a ratio is a quantitative relation between two elements of the same core (Arnaud et al. 2015), it does not depend on analytical factors and can be utilized to compare with ratios among other samples. To conduct such a comparison along with every sand-event sheet, we applied LDA through the predominant elements in PCA, normalized by Ta (for the use of Ta as normalization element, see the discussion in the body text).

\subsection{Grain size analysis}

Each sand layer was divided into slices of $1 \mathrm{~cm}$ thick. A cubic sample of $1.5 \mathrm{~cm}$ wide and $2 \mathrm{~cm}$ depth was extracted from every slice, with $3.5 \mathrm{~g}$ of dry sample on average. Prior to the grain size analysis, samples were treated to remove organic matter and carbonate content by dissolution in $10 \%$ hydrogen peroxide $\left(\mathrm{H}_{2} \mathrm{O}_{2}\right)$, desiccation at $60^{\circ} \mathrm{C}$ for $12 \mathrm{~h}$, and homogenization by mixing with a spatula for $1 \mathrm{~min}$. Subsequently, we utilized a sample splitter to obtain a suitable amount of sediment for the laser equipment. The sample was divided in two half-lots three times to obtain approximately $0.5 \mathrm{~g}$ of dry sample. Subsequently, we utilized the sediment sieving method to separate particles $>2000 \mu \mathrm{m}$ to adequately characterize smaller particles with laser diffraction (Gerlach et al. 2002). We utilized a laser diffraction analyzer (Shimadzu SALD-2300, Japan) at Tohoku University. The resolution of the equipment ranges from $17 \mathrm{~nm}$ to $2500 \mu \mathrm{m}$. Grain size results were processed in GRADISTAT v8 (Blott and Pye 2001) to obtain the grain size distribution, mean, sorting, kurtosis, and skewness. GRADISTAT implements the classification methods of the Folk-Ward and moments.

\subsection{XRD analysis}

A total of $5 \mathrm{~g}$ was extracted from each sand layer for homogenization. Sampling was conducted throughout the entire layer to obtain a representative lithological composition. 
XRD analyses were conducted on the powder and oriented samples extracted from the sand layers. To separate and orientate the clay-size portion from the sediment sand layers, we followed the sample preparation technique proposed by Moore and Reynolds (1999). First, we disaggregated the unconsolidated minerals and homogenized the samples with a bead cell disrupter. Afterward, $2 \mathrm{~g}$ of the sample was dispersed by ultrasound in pure water. After the decantation of the heavier minerals, the suspended material was centrifuged and filtered using Millipore ${ }^{\mathrm{TM}}$. Finally, the clay-portion was transferred to the glass slide.

The oriented samples were treated and analyzed in three stages: air-dried, ethylene glycol solvated for smectite identification, and heated to $550^{\circ} \mathrm{C}$ for $3 \mathrm{~h}$ for kaolinite identification. We utilized the diffractometer from the Earth Science Department of Tohoku University (Philips X'pert Pro MPD, USA). The measuring resolution was $0.5 \mathrm{~min}$ every degree, from $0^{\circ}$ to $35^{\circ} 2 \theta$. The resulting patterns were processed and interpreted using the Match! software (Crystal Impact GbR, Germany)

\subsection{Diatom analysis and shell fragments recognition}

The separation and preparation method applied for diatom analysis was based on the methodology proposed by Kosugi (1993). The sub-samples were treated with $15 \% \mathrm{H}_{2} \mathrm{O}_{2}$, and the cleaned diatom valves were mounted on Pleurax. For each sub-sample, at least 300 valves were identified and counted. Diatom species were identified according to the studies of Patrick and Reimer (1966), Akiba (1986), Kammer and Lange-Bertalot (1986), Simonsen (1987), Kammer and Lange-Bertalot (1988), Kammer and Lange-Bertalot (1991b; 1991a), Lange-Bertalot (1993), Lange-Bertalot and Moser (1994), Reichart (1995), Lange-Bertalot et al. (1996), Lange-Bertalot and Genkal (1999), Reichart (1999), Witkowski et al. (2000), Lange-Bertalot (2001), Lange-Bertalot et al. (2003), Levkov et al. (2003), Nagumo (2003), Mann et al. (2004), Tanaka and Nagumo (2004), Watanabe et al. (2005), Kobayashi et al. (2006), and Levkov et al. (2007). After identification and counting, we grouped the species according to their environment as freshwater, freshwater-brackish, and brackish-marine.

Shell fragment recognition was conducted with two objectives: evidence of marine influence and high-energy surges. The shell fragments were separated and identified using a trinocular microscope.

\subsection{Carbonate quantification}

Carbonate content was calculated by controlling pH dissolution. To fix the pH to 5.2 , we used a solution of $500 \mathrm{ml}$ of $2 \%$ acetic acid $\left(\mathrm{CH}_{3} \mathrm{COOH}\right)$ and $6.5 \mathrm{~g}$ of ammonium acetate $\left(\mathrm{CH}_{3} \mathrm{COONH}_{4}\right)$. Each sample $(200 \mathrm{~g})$ was poured into $100 \mathrm{ml}$ of solution for $24 \mathrm{~h}$. The sample was further dehydrated using a $0.8 \mu \mathrm{m}$ Millipore ${ }^{\mathrm{TM}}$ filter and desiccated at $24^{\circ} \mathrm{C}$ for $24 \mathrm{~h}$. Finally, the carbonate content was obtained by subtracting the initial and final weights.

\subsection{Tephra analysis}

The petrological characteristics of the tephra layers were obtained via mineralogy analysis, heavy mineral content, volcanic glass shape, and refractive index of glass shards, hornblende, and orthopyroxene crystals. The obtained data were further correlated with standardized values of known tephra layers in Japan. Kyoto Fission-Track Co., Ltd. conducted the analyses.

\subsection{Radiocarbon dating}

Bulk samples were obtained from the interbedding peaty-mud layers for ${ }^{14} \mathrm{C}$ dating. Slices of $1 \mathrm{~cm}$ wide and $5 \mathrm{~mm}$ thick were extracted. The samples were treated with an acid wash to remove the bone collagen and cellulose. Furthermore, ${ }^{14} \mathrm{C}$ dating was conducted using accelerator mass spectrometry (AMS) in Beta Analytic Inc.

We employed Oxcal 4.3.2 (Bronk Ramsey 2017) to calibrate dating results to calendar ages and applied the calibration curve dataset IntCal13 (Reimer et al. 2013). The sequence model (Lienkaemper and Ramsey 2009) was used to calculate the estimated deposition age of the sand layers (Lienkaemper and Ramsey 2009). In addition, using Oxcal, it was possible to obtain probabilistic recurrence intervals for deposition ages for every sand unit using the "Date" command.

\section{Results}

\subsection{GPR, core sampling, and sedimentary features}

Thirteen GPR lines and core samples were collected from the survey area. Thirteen core samples (H01-H13) were obtained. Core sample Ha8 was obtained in a preliminary recognition of the area at the same point as $\mathrm{H} 02$ (Shinohara et al. 2017). These core samples were described in the field and analyzed in the laboratory.

GPR profile images revealed two major features regarding the stratigraphic configuration (Fig. 3a): first, small basins associated with large depths of the paleosurfaces and thus locations with better preservation potential of sediments; second, the presence of two strong reflectors in the sedimentary sequence.

The relative positions of the core samples are illustrated in Fig. 3b. The general sedimentological characteristics of the sand layers found in core samples Ha8, $\mathrm{H02}, \mathrm{H03}, \mathrm{H04}$, and $\mathrm{H06}$ are described in Table 1. As stated in the Methods section, these cores were later used for the laboratory analyses. Core samples Ha8 and $\mathrm{HO} 2$ contained the largest number of sand layers among the core samples taken (Fig. 3c), with ten layers. Core samples $\mathrm{H} 03$, $\mathrm{H} 04$, and $\mathrm{H06}$ contained seven, five, and one sand layers, respectively. The sedimentary record generally displayed a succession of two or three tephra layers at the top; the following section comprised intercalation among sand layers and peaty-mud, with occasional ashy tephras and a final thick tephra layer at the bottom.

As core sample $\mathrm{H} 02$ contained the most representative sedimentary succession (Fig. 3b and 3c), it can be described as follows: the upper part of the core sample $\mathrm{H} 02$ was characterized by cultivated soil, followed by a succession of three thick tephra layers (T1, T2, and T3) along with two interbedding thin mud 
beds. The underlying sequence comprised the interbedding of sand and peaty-mud, along with two tephra beds (T4 and T5). Within this section, it was possible to recognize eight sand layers with the naked eye, named as units S1, S2, S4, S5, S7, S8, S9, and S10 from top to bottom. Units S3 and S6 in H02 were recognized by a magnifying glass, and their boundaries were later constrained by ITRAX and CT images (see the discussion section in the body text). The bottommost section was formed by a thick tephra layer (T6).

\subsection{CT, MS, geochemistry, and grain size analysis}

X-ray CT, MS, ITRAX, and grain size analyses were conducted on core samples H02, H03, H04, and H06.

The CT image reconstruction of core samples $\mathrm{H02}, \mathrm{H03}$, and $\mathrm{HO} 4$ is shown in Fig. 4. Yellow and green colors represent the presence of sand layers. Dark blue denotes peaty mud, and gray-blue indicates tephra layers. Red cumulates correspond to roots. Color-intensity changes in the sand layers generally exhibit compositional changes and grain size variations.

In CT reconstruction, it is possible to recognize the sand units (light green in CT color), interbedded non-bioturbated mud (royal blue in CT color), and tephra layers (dark blue-gray in CT color). Sedimentological characteristics such as geological contacts (planar, erosive, or transitional), intraclasts, and grain size changes of core $\mathrm{H} 02$ have also been delineated and shown in Fig. 4. Sand layers S3 and S6 were highlighted in the CT image, which allowed the boundaries to be constrained. The mud layer separated units S8 and S7 by the presence of sand aggregates, indicating bioturbation. Between units S6 and S7, the color defined the presence of T4 and S5. Thus, there is a considerable increase in the intensity of bioturbation, as evidenced by the heterogeneity of the sand layers. Units S2 and S3 are cut by roots (Fig. 4).

High values of MS in core H02 can be linked to the presence of sand layers S4 to S10 (Figs. 5 and 6). 
Table 2

Summary of sedimentological, paleontological and geochemical analysis of the event sand layers (S1 to S10). For lateral correlation of the sand layers S1 to $\subseteq$ in the body text.

\begin{tabular}{|c|c|c|c|c|c|c|c|c|c|c|}
\hline \multirow[t]{2}{*}{$\begin{array}{l}\text { Sand } \\
\text { unit }\end{array}$} & \multicolumn{3}{|c|}{ Grain Size Analysis } & \multicolumn{2}{|c|}{ Computed Tomography } & \multirow{2}{*}{$\begin{array}{l}\text { Paleontological } \\
\text { indicators: } \\
\text { marine diatom } \\
\text { species / shell } \\
\text { fragments }\end{array}$} & \multirow[t]{2}{*}{$\begin{array}{l}\text { Carbonate } \\
\text { content }\end{array}$} & \multirow{2}{*}{$\begin{array}{l}\text { Magnetic } \\
\text { Susceptibility } \\
\text { Lateral } \\
\text { change }\end{array}$} & \multicolumn{2}{|c|}{$\begin{array}{l}\text { Micro X-Ray fluorescenc } \\
\text { (description for the main }\end{array}$} \\
\hline & Grading & $\begin{array}{l}\text { Sorting } \\
\text { vertical } \\
\text { change }\end{array}$ & $\begin{array}{l}\text { Thickness } \\
\text { change }\end{array}$ & $\begin{array}{l}\text { Basal } \\
\text { contact }\end{array}$ & $\begin{array}{l}\text { Flow } \\
\text { structures }\end{array}$ & & & & Titanium & Rubidium \\
\hline S1 & Massive & $\begin{array}{l}\text { No } \\
\text { change }\end{array}$ & $\begin{array}{l}\text { Not } \\
\text { continuous }\end{array}$ & Bioturbated & Not visible & - & - & - & $\begin{array}{l}\text { No } \\
\text { change }\end{array}$ & Peak \\
\hline S2 & Massive & $\begin{array}{l}\text { No } \\
\text { change }\end{array}$ & $\begin{array}{l}\text { Not } \\
\text { continuous }\end{array}$ & Bioturbated & Not visible & - & - & - & $\begin{array}{l}\text { No } \\
\text { change }\end{array}$ & Peak \\
\hline S3 & Massive & $\begin{array}{l}\text { No } \\
\text { change }\end{array}$ & $\begin{array}{l}\text { Not } \\
\text { continuous }\end{array}$ & Bioturbated & Not visible & - & - & - & $\begin{array}{l}\text { No } \\
\text { change }\end{array}$ & Peak \\
\hline S4 & Massive & $\begin{array}{l}\text { Upward } \\
\text { increase }\end{array}$ & $\begin{array}{l}\text { Landward } \\
\text { thinning }\end{array}$ & Bioturbated & Not visible & - & $0,1 \%$ & $\begin{array}{l}\text { Landward } \\
\text { decrease }\end{array}$ & Constant & Constant \\
\hline S5 & $\begin{array}{l}\text { Upward } \\
\text { fining } \\
\text { (skewness } \\
\text { variation } \\
\text { and phi } \\
\text { mode } \\
\text { change) }\end{array}$ & $\begin{array}{l}\text { Upward } \\
\text { sorting } \\
\text { decrease } \\
\text { - } \\
\text { presence } \\
\text { of coarse } \\
\text { pumice } \\
\text { towards } \\
\text { the top }\end{array}$ & $\begin{array}{l}\text { Landward } \\
\text { thinning }\end{array}$ & Erosive & Not visible & $\begin{array}{l}1 \text { specie } \\
\text { (Fallacia sp.) / } \\
\text { shell fragment } \\
\text { (Fig. 11) }\end{array}$ & $0,2 \%$ & $\begin{array}{l}\text { Landward } \\
\text { decrease }\end{array}$ & $\begin{array}{l}\text { Upward } \\
\text { reduction }\end{array}$ & $\begin{array}{l}\text { Upward } \\
\text { increase }\end{array}$ \\
\hline S6 & Constant & $\begin{array}{l}\text { No } \\
\text { change }\end{array}$ & $\begin{array}{l}\text { Landward } \\
\text { thinning }\end{array}$ & $\begin{array}{l}\text { Planar } \\
\text { contact }\end{array}$ & Not visible & Not recorded & $0 \%$ & $\begin{array}{l}\text { Landward } \\
\text { decrease }\end{array}$ & Constant & Peak \\
\hline S7 & $\begin{array}{l}\text { Upward } \\
\text { coarsening } \\
\text { at } \mathrm{H} 02\end{array}$ & $\begin{array}{l}\text { Upward } \\
\text { increase }\end{array}$ & $\begin{array}{l}\text { Landward } \\
\text { thinning }\end{array}$ & Bioturbated & Not visible & $\begin{array}{l}3 \text { species } \\
\text { (Adoneis sp.; } \\
\text { Fallacia sp.; } \\
\text { Melosira } \\
\text { moniliformis) }\end{array}$ & $0 \%$ & $\begin{array}{l}\text { Landward } \\
\text { increase - } \\
\text { decrease }\end{array}$ & $\begin{array}{l}\text { Slightly } \\
\text { upward } \\
\text { increase }\end{array}$ & $\begin{array}{l}\text { Upward } \\
\text { decrease }\end{array}$ \\
\hline S9 & Massive & $\begin{array}{l}\text { No } \\
\text { change }\end{array}$ & $\begin{array}{l}\text { Landward } \\
\text { thickening } \\
\text { and } \\
\text { thinning }\end{array}$ & $\begin{array}{l}\text { Erosive. } \\
\text { Erosive } \\
\text { surface } \\
\text { bounding } \\
\text { the two } \\
\text { subunits }\end{array}$ & $\begin{array}{l}\text { Rip-up clast } \\
\text { in the } \\
\text { interbedding } \\
\text { mud-layer, } \\
\text { flame } \\
\text { structure }\end{array}$ & $\begin{array}{l}1 \text { specie } \\
\text { (Adoneis sp.) }\end{array}$ & $0,1 \%$ & $\begin{array}{l}\text { Not } \\
\text { significant } \\
\text { change }\end{array}$ & $\begin{array}{l}\text { Upward } \\
\text { reduction } \\
\text { in two } \\
\text { pulses }\end{array}$ & Peak \\
\hline S10 & $\begin{array}{l}\text { Upward } \\
\text { fining in } \\
\text { the distal } \\
\text { core } \\
\text { sample } \\
\text { (H04) }\end{array}$ & $\begin{array}{l}\text { No } \\
\text { change }\end{array}$ & $\begin{array}{l}\text { Landward } \\
\text { thinning }\end{array}$ & Erosive & Not visible & $\begin{array}{l}2 \text { species } \\
\text { (Adoneis sp.; } \\
\text { Melosira } \\
\text { moniliformis) }\end{array}$ & $0,3 \%$ & $\begin{array}{l}\text { Landward } \\
\text { decrease }\end{array}$ & $\begin{array}{l}\text { Upward } \\
\text { reduction, } \\
\text { increase } \\
\text { and } \\
\text { constant }\end{array}$ & $\begin{array}{l}\text { Upward } \\
\text { increase }\end{array}$ \\
\hline
\end{tabular}

ITRAX elemental patterns obtained from core $\mathrm{H} 02$ exhibited conspicuous changes related to the interface between the peaty-mud and the sand layers. Si, Ca, $\mathrm{Sr}, \mathrm{K}, \mathrm{Ti}$, and $\mathrm{Fe}$ had higher values on sands, whereas $\mathrm{Ta}$ and $\mathrm{Cl}$ exhibited lower values (Fig. 6). Elemental changes also contributed in differentiating S3 and S6 from the neighboring mud layers. Fluctuation pattern of Sr was relatively similar to that of $\mathrm{Ca}$. Ti exhibited the most remarkable changes among the elements measured; every sand layer can be characterized by an abrupt change in Ti across, over, and underlying mud beds. Although it was not possible to identify significant changes in the Rb DFT between the lithological layers, it exhibited some changes throughout the sand layers, proportionally with the mud increase. However, high Ta values were related to peaty-mud layers. CI DTF pattern exhibited low values in the sand layers and high values in the peaty-mud layers. A ratio of $\mathrm{Ca}$ to Ta was introduced to clearly delineate the interface between sand and peaty mud. High Mo inc/coh ratio values represented the high relative content of organic matter in the peaty-mud layers. Although sand layers were characterized by low Mo inc/coh intensity, the pattern behaved oppositely to $\mathrm{Ca}$, Ti, and $\mathrm{Ca} / \mathrm{Ta}$. We applied PCA for the XRF data obtained on the cores $\mathrm{H} 02, \mathrm{H} 03$, $\mathrm{H} 04$, and $\mathrm{H} 06$.

The gray value profile extracted from CT (Fig. 6) displayed high values related to the sand layers. As stated before, the gray value was directly related to the relative density determined by X-ray scattering. This illustrates the grain size variation, lithology changes, and packing. 
The vertical variations in MS (Fig. 5), elemental composition (Fig. 6), and CT color intensity (Fig. 4) were linked to the changes in grain size (Fig. 7) within the sand layers.

Grain size analysis was conducted in cores $\mathrm{H02}, \mathrm{H03}$, and $\mathrm{H0} 4$ to identify vertical and landward changes in each sample. Some sand layers (e.g., S1, S2, and $\mathrm{S} 3 \mathrm{in} \mathrm{H02)}$ were not sliced and analyzed by grain size owing to the nominal thickness of the layer. In addition, sand layers in core sample H06 were not analyzed because of the high bioturbation and mixing with peaty mud. Regarding the sample processing, although it is expected that the sample splitter produces a minor overall inaccuracy level among the splitting methods, some segregation could have occurred because of the number of times the sample was divided; nonetheless, it is expected that the confidence level is not greater than $2 \%$ (Gerlach et al. 2002).

Grain size analysis revealed that the sand layers are mostly composed of sand with grain sizes of 1.5-2.0 phi, which frequently exhibit upward fining (Fig. 7). Thicker sand layers, such as S8b and S5 at H02, typically exhibited normal or inverse grading. In addition, the sand layers exhibited vertical changes in mode values (Fig. 7). Notably, the mode value (in the phi scale) shown in Fig. 7 corresponded to the particle size with the highest frequency in the grain size distribution curve. Some curves exhibited multimodal grain-size distribution, primarily related to sand-mud mixing or sand-granule mixing. As observed in S4, S5, and S8, in addition to grading, skewness and kurtosis exhibited a vertical variation in the sorting in the sand layers (Fig. 7).

In Table 2, the specific characteristics of each sand layer with respect to geochemistry, MS, CT, and grain size are described. Not all features are observed in every proxy.

\subsection{PCA and linear component analysis}

The PCA results for core $\mathrm{H02}$ are shown in Fig. 8 . The first three principal components represented $65 \%$ of the total variability, with distributions of $35 \%, 16 \%$, and $15 \%$, respectively. After using several combinations of elements, it was not possible to separate the sand layers in the clusters (Fig. 8). Nonetheless, although the cloud of data is averaged to the center, the data illustrated the tendency of unit S8 to move to Sr and Ca. Units S1, S2, and S3 were inclined to be associated with $\mathrm{Cr}$, Ta, and Zr. Furthermore, S4 moved to Fe and Ti.

We applied LDA to the predominant elements in PCA ( $\mathrm{Si}, \mathrm{Ca}, \mathrm{Sr}, \mathrm{Cr}, \mathrm{Rb}, \mathrm{Zr}, \mathrm{Cr}$, Ti, and Fe), normalized by $\mathrm{Ta}$ (see the discussion in the body text), which behaved opposite to sand-related elements in the ITRAX results. LDA exhibited the geochemical correlation between the sand layers among the core samples (Fig. 9).

Although units S1 and S2 do not appear in the other core samples, LDA revealed that these sand units do not have a geochemical correlation with the other sand layers.

\subsection{XRD}

XRD analyses were conducted on sand layers S2, S4, S5, S7, S8, S9, and S10 in core samples H02 and H04.

Even after the separation of clay portion, plagioclase (varying compositionally from albite to andesine) and quartz were highly representative in every sample.

Kaolinite was recognized in all sand layers (see Appendix 2). However, pure illite or pure smectite was not observed. Mixed-layered clay minerals such as kaolinite-montmorillonite, montmorillonite-chlorite, and illite-smectite (rectorite) were identified in different proportions among the sand layers. Glauconite appeared in units S4, S5, S6, S7, S8, S9, and S10.

\subsection{Micropaleontological analyses}

Diatom analysis was conducted on 24 sub-samples obtained from the core sample Ha8. Diatom species related to freshwater (34 species), freshwaterbrackish (3 species), and brackish-marine (5 species) environments were identified in core sample Ha8 (Fig. 10). Both freshwater and freshwater-brackish species were found in sand layers, peaty mud, and tephra layers. Brackish-marine (B-M) species were identified mostly in the sand layers. The B-M species found in the sand units are described in detail in Table 2 and Fig. 10. The proportional amount of the B-M species with respect to the total found species was $<10 \%$ in every sample of every sand layer.

Along with the beds of S2, S5, S7, S9, and S10, it is possible to identify the presence of freshwater diatom species. In S5, freshwater species was related to the middle part and in $\mathrm{S} 8$, the presence of such species was related to the base and top of the bed.

Using a trinocular microscope, a shell fragment of the bivalve was recognized in unit S5 (Fig. 11). In the other sand layers, it was not possible to find any mollusk fragments.

Carbonate content was identified on units S4, S5, S6, S7, S8, S9, and S10 at H02. Units S6, S7, and S8 exhibited a 0 wt \% carbonate content. Meanwhile, in units S4, S5, S9 and, S10 the recorded value was $<0.3 \%$ (Table 2).

\subsection{Tephra Analysis}

Tephra layers at the top and base of the core samples were sampled in Ha8 for identification. Tephra analysis revealed that both tephra layers are related to the eruptive events of the Towada Volcano. Based on the petrological analysis (mineralogy, heavy mineral content, volcanic glass shape, and refractive index of glass shards, hornblende, and orthopyroxene crystals), T1 was identified as To-a, whose age is AD915 (Machida and Arai 2003). In addition, basal tephra was associated with To-cu, with a deposition age of 6200 BP (Kudo and Sasaki 2007) (Table 3). 
Table 3

Results of tephra analysis for T1 and T6.

\begin{tabular}{|lllll|}
\hline Tephra layer & Refractive index & Volcanic glass & Remarks & Classification \\
\hline T1 & 1504 & T, C, H, It & Heavy minerals: Opx, Opq, Cpx>GHb & Towada-a (To-a) \\
& 1507 & T, C, H > It & Light minerals: $\mathrm{Pl}, \mathrm{Qz}$ & \\
\hline T6 & 1513 & T>C & Heavy minerals: Opx, Opq, Cpx>Ap & Towada-cu (To-cu) \\
& & & Light minerals: $\mathrm{Pl}, \mathrm{Qz}$ & \\
\hline
\end{tabular}

Isopach map of tephra distribution is shown in Fig. 1. According to the reported isopach map by Machida and Arai (2003), the thickness of the To-a tephra in Hachinohe should be $<5 \mathrm{~cm}$. Nonetheless, the stratigraphic profile depicted a layer of $\sim 35 \mathrm{~cm}$. In contrast, the To-cu tephra thickness should be $<10 \mathrm{~cm}$; however, the reported layer was observed to be $>40 \mathrm{~cm}$.

\section{7 ${ }^{14} \mathrm{C}$ Dating}

A total of 11 samples were obtained from core sample Ha8 for the deposition age modeling. Three samples from $\mathrm{H} 04$ and two from $\mathrm{H} 02$ were utilized for the lateral correlation.

The conventional radiocarbon ages obtained from core samples $\mathrm{H02}$, Ha8, and $\mathrm{HO} 4$ are listed in Table 4. The calibrated results are shown in Fig. 12. The following dates corresponded to modeled depositional dates for sand layers, with a probability of 95.4\%: unit S1: 1241-1932 cal BP; unit S2: 1946-2770 cal BP; unit S4: 2771-3066 cal BP; unit S5: 3025-3515 cal BP; unit S6: 3523-3775 cal BP; unit S7: 3828-4364 cal BP; unit S8: 42924773 cal BP; unit S9: 46885016 cal BP; unit S10: 4942-5536 cal BP. Based on the tephra analysis results, the model calculation was constrained by To-a and To-cu events at the base and top of the sedimentary sequence. Owing to the minor thickness of S3 and its adjacent peaty-mud layers, it was not possible to constrain its deposition age. The probabilistic recurrence intervals for the sand units are listed in Table 5.

Table 4

Conventional radiocarbon ages obtained from the core samples $\mathrm{H02}$, $\mathrm{Ha} 8$ and $\mathrm{HO} 4$.

\begin{tabular}{|lllll|}
\hline Sample ID & Type of material & Pretreatment & \multicolumn{1}{|c|}{$\sigma 13 \mathrm{C}(\%)$} & Conventional radiocarbon age \\
\hline H02/1 & Organic sediment & Acid washes & -26.30 & $2830+/-30$ \\
\hline H02/2 & Organic sediment & Acid washes & -27.04 & $4400+/-30$ \\
\hline Ha8/C1 & Organic sediment & Acid washes & -19.5 & $1280+/-30$ \\
\hline Ha8/C2 & Organic sediment & Acid washes & -25.2 & $1770+/-30$ \\
\hline Ha8/C3 & Organic sediment & Acid washes & -25.7 & $1990+/-30$ \\
\hline Ha8/C4 & Organic sediment & Acid washes & -26.2 & $2690+/-30$ \\
\hline Ha8/C5 & Organic sediment & Acid washes & -26.6 & $2900+/-30$ \\
\hline Ha8/C6 & Organic sediment & Acid washes & -26.4 & $3270+/-30$ \\
\hline Ha8/C7 & Organic sediment & Acid washes & -26.8 & $3550+/-30$ \\
\hline Ha8/C8 & Organic sediment & Acid washes & -26.6 & $3890+/-30$ \\
\hline Ha8/C9 & Organic sediment & Acid washes & -26.9 & $4210+/-30$ \\
\hline Ha8/C10 & Organic sediment & Acid washes & -27.0 & $4390+/-30$ \\
\hline Ha8/C11 & Organic sediment & Acid washes & -26.9 & $4760+/-30$ \\
\hline H04/1 & Organic sediment & Acid washes & -28.00 & $3160+/-30$ \\
\hline H04/2 & Organic sediment & Acid washes & -26.78 & $3190+/-30$ \\
\hline H04/3 & Organic sediment & Acid washes & -27.29 & $4300+/-30$ \\
\hline
\end{tabular}


Table 5

Probabilistic recurrence between sand units.

\begin{tabular}{|lll|}
\hline Probability & $(1 \sigma)$ & $(2 \sigma)$ \\
& $\mathbf{6 8 . 2 0} \%$ & $\mathbf{9 5 . 4 0 \%}$ \\
\hline Unit S1 - Unit S2 & 690 & 1240 \\
\hline Unit S2 - Unit S4 & 591 & 920 \\
\hline Unit S4 - Unit S5 & 338 & 578 \\
\hline Unit S5 - Unit S6 & 363 & 654 \\
\hline Unit S6 - Unit S7 & 381 & 676 \\
\hline Unit S7 - Unit S8 & 408 & 736 \\
\hline Unit S8 - Unit S9 & 310 & 545 \\
\hline Unit S9 - Unit S10 & 399 & 668 \\
\hline Total average & 435 & 752 \\
\hline Average from S4 to S10 & 367 & 643 \\
\hline
\end{tabular}

Based on the dating results, sand and tephra layers were removed to obtain the sedimentation rate for the area by calculating the slope of the linear trendline (Fig. 13). The sedimentation rate was nearly constant, with an average rate of $82 \mathrm{~mm} / \mathrm{kyr}$.

\section{Discussion}

\subsection{Sand events correlation}

Based on the GPR image, the two strong reflectors identified were interpreted as the interfaces between the middle sand-peaty mud sequence with the upper tephra-mud sequence and the lower thick tephra (Fig. 3a). Further, the initial lateral correlation of the sand-peaty mud sequence was conducted based on sedimentary features, color, and stratigraphic position (Fig. 3c). The persistent presence of tephra layer four (T4) among several cores served as a marker horizon. Table 6 presents the lateral correlations among the core samples. 


\section{Sand Correlation analysis}

layer

T1 It was defined as the Towada-a event (Table 3). It continues throughout all of the core samples (Fig. 3), just below the paddy field soil. It is also consistent that two more tephra events were found underlying it, interbedded with peaty mud, except in $\mathrm{H} 13, \mathrm{H} 07$, and $\mathrm{H} 06$, where there was only one, probably due to erosion.

S1 It only appears in the core sample H02 (the thickest sedimentary record). It is difficult to identify a lateral continuity, essentially due to its thickness (Table 1, Fig. 3).

S2 It was traced among $\mathrm{H} 02, \mathrm{H} 01$ and $\mathrm{H} 07$, mainly due to its relative stratigraphic position and lithological characteristic.

S3 It only appears in the core sample H02 (the thickest sedimentary record). It is difficult to identify a lateral continuity, essentially due to its thickness.

S4 It was traceable among $\mathrm{H02}, \mathrm{H01}, \mathrm{HO}, \mathrm{H08}$, and $\mathrm{HO}$ (Fig. 3). Such correlation was made on the grain size, color and relative stratigraphic position.

S5 It was traced throughout all of the core samples, representing the sand with the furthest extent. It is the second thickest sand layer, after S8, in the sedimentary sequence. Its position just above the peaty-mud layer and T4 (marking horizon), upward fining, and bottom erosive contact allowed its lateral correlation. The dating result obtained from the peaty-mud layer underlying S5 between $\mathrm{Ha} 8$ and $\mathrm{H} 04$ and the supported the correlation (see the discussion section in the body text).

T4 It is a consistent ash layer, defined as a white clay with homogeneous thickness among the sand layers. Due to its consistency, lateral continuity, and lithological characteristics, it was used as a marker horizon to define the upper boundary of S6 and the lower boundary of S5, taking into account the peaty mud interbedding between the sand and tephra layers (Table 1, Fig. 3).

S6 It is located below the peaty mud underlying T4; it was found in the core samples H02 and H03. Such correlation was made based on the characteristic lenticular stratification, silt composition, and the thickness of the layers (Table 1).

S7 It was traceable among $\mathrm{H02}, \mathrm{H01}, \mathrm{H07}, \mathrm{H0}, \mathrm{H03}, \mathrm{H09}, \mathrm{H} 10$, and $\mathrm{H0}$ (Fig. 3). Grain size, the bottom transitional or erosional contact, and the relative stratigraphic position led to its lateral correlation.

S8 It was traceable throughout all the core samples between $\mathrm{H} 02$ and $\mathrm{H} 06$ and represented, in general, the thickest sand layer. Its thickness, upward fining, and relative stratigraphic position allowed its lateral correlation.

S9 It was traceable among the core samples $\mathrm{H02}, \mathrm{H} 08, \mathrm{HO}, \mathrm{H} 10$, and $\mathrm{HO}$. The two thin laminas interbedded with the thin peaty mud led to the correlation between $\mathrm{HO} 2$ and $\mathrm{H} 03$. The stratigraphic position allowed the correlation among the other core samples. The dating result obtained from the peaty-mud layer underlying S 9 and overlying S10 in $\mathrm{Ha} 8$ and $\mathrm{H} 04$ supported the correlation (see the discussion section in the body text).

S10 It was traceable among the core samples $\mathrm{H02}, \mathrm{H0}, \mathrm{HO}, \mathrm{H} 10$, and $\mathrm{H04}$. The stratigraphic position, overlying To-cu and the peaty mud, led to the lateral correlation. The dating result obtained from the peaty-mud layer underlying S 9 and overlying S10 in Ha8 and $\mathrm{H0} 4$ supported the correlation (see the discussion section in the body text).

T6 It was defined as the Towada-cu event (Table 3). It continues throughout all the core samples at the end of the sequence. In all of the cases, it was found as a thick lapilli layer.

Table 6.

The correlation was confirmed and supported with $\mathrm{CT}$, geochemical analysis, and radiocarbon dating, as will be described as follows.

\subsubsection{Correlation between core samples $\mathrm{HO2}$ and Ha8}

As the core sample Ha8 was the first core to be extracted, diatom analysis, tephra analysis, and radiocarbon dating for event recurrence was conducted on this core sample. The GPS coordinates indicated that the sampling site was the same for $\mathrm{H} 02$ and $\mathrm{Ha} 8$ (+/- $2 \mathrm{~m})$.

The correlation with the adjacent $\mathrm{H} 02$ was determined based on the stratigraphic position of the sand layers, lithology, and sedimentary characteristics (Fig. 3, Table 1). Sand layers above S5 were correlated using the relative stratigraphic position because the lithological characteristics of the first four layers were identical. The mud layer above S5 in $\mathrm{H} 02$ can be correlated to the one overlying S5 in Ha8, with ages ranging from 2800 to 3000 cal BP and 3075 to 2973 cal $\mathrm{BP}$, respectively.

In addition, T4 was below S5 in both cores, and it was used as a marker horizon (Fig. 3b). S6 was correlated based on the stratigraphic position below T4 and the sedimentary characteristics. The dating result between S8 and S7 in $\mathrm{H02}$ did not coincide with the same stratigraphic position in Ha8. In contrast, such dating results coincided with the peaty-mud layer between S8 and S9 in Ha8. Nonetheless, the age difference is small, which could be related to the close time frame or reworking of sedimentary events during sand event deposition. However, it supports the correlation of S8 as it was deposited after 4892 cal BP, and the sedimentary characteristics of the layers coincide. In both cores, both S9 and S10 appear as thin beds underlying S8.

In general, the thickness of the sand layers changed considerably between the two core samples. S3 was not recognizable in Ha8, and S6 was significantly reduced in thickness to a medium lamina (Fig. 3b). Such fast lateral changes in thickness are common in tsunami deposits (Nakamura et al. 2012).

\subsubsection{Lateral correlation of cores $\mathrm{H} 02, \mathrm{H} 03, \mathrm{H} 04$ and $\mathrm{H} 06$ using LDA and ${ }^{14} \mathrm{C}$}

The ITRAX results and its analysis by LDA partially supported the initial correlation based on sedimentary features and stratigraphic relationships. LDA displayed a clear geochemical correlation of events S5 and S8 among core samples H02, H03, and H04 (Fig. 9). Nonetheless, events S5 and S8 in H06 cannot be explicitly linked to their corresponding levels in the other cores because of their closeness to other samples in the LDA classification. On the other hand, 
LDA evidenced a substantial geochemical similarity among the sands S6, S7, S9, and S10 in different cores, suggesting a similar lithological composition, and thus the source of the sediments. On the other hand, S4 in core H02 lacks a good correlation with the corresponding depth in H03 (Fig. 4), implying that the furthest landward sand could correspond to a different sedimentary event and source. Therefore, clustering must be made carefully to avoid the false correlation of sand layers. Nevertheless, LDA clustering is useful to find considerable differences among the samples, which suggests the need to confirm the reliability of the correlation, as seen in S4 (Fig. 9).

As for the correlation between $\mathrm{Ha} 8$ and $\mathrm{H} 02$, the ${ }^{14} \mathrm{C}$ dating results supported the lateral correlation of the sand layers (Fig. 14). In addition, the mud layer overlying S10 in Ha8 can be correlated to the same stratigraphic layer in H04, with age ranges of 4892-5034 cal BP and 4854-4960 cal BP, respectively. Calibrated ages show that the peaty-mud layers underlying S5 in $\mathrm{Ha} 8$ and $\mathrm{H0} 4$ are coetaneous. On the other hand, the dating result from the peat -mud underlying $\mathrm{S} 7 \mathrm{in} \mathrm{H0} 4$ does not correspond to the age obtained on the same stratigraphic level on Ha8. As stated previously, differences in some dating ages among core samples $\mathrm{H02}, \mathrm{Ha} 8$, and $\mathrm{H0} 4$ may be related to the reworking of the sampled material (Ishizawa et al. 2018), sediment erosion due to tsunami (Naruse et al. 2012), or sampling resolution (Fig. 14) (i.e., mud layers underlying S8 in H02 and Ha8 and mud layers underlying S7 in Ha8 and H04).

As the remaining cores (i.e., $\mathrm{H} 13, \mathrm{H} 01, \mathrm{H} 07, \mathrm{H} 08, \mathrm{H} 09$, $\mathrm{H} 10, \mathrm{H} 11, \mathrm{H} 12$, and $\mathrm{H} 05$ ) are intercalated with the core samples $\mathrm{H} 02$, $\mathrm{H} 03$, $\mathrm{H} 04$, and $\mathrm{H} 06$ (Fig. $3 \mathrm{~b}$ ), we utilized the results from radiocarbon dating, the position of $\mathrm{T} 4$, along with the sedimentary characteristics and stratigraphic position of the sand layers as critical elements for their lateral correlation.

\subsection{Identification of tsunami origin}

We consider marine diatom species, shell fragments, glauconite occurrence, landward thinning, and landward reduction of MS value as strong evidence of marine provenance of the sand layer (Table 2). Regarding marine provenance, a factual imprint is the presence of fragments or complete structures of marine organisms, which is, in our case, diatom species and shell fragments, respectively. Complementarily, glauconite also exhibits the marine origin of the sand layers by being an authigenic mineral of shallow oceanic platform environments (Huggett 2013).

Sand units S4, S5, S7, S8, S9, and S10 display landward reduction of its MS values among the core samples H02, H03, H04, and H06 (Fig. 5), indicating the direction of the density gradation during the wave progression. On the other hand, the maximum magnetic susceptibility for S6 was obtained from H02, which is located in the middle of the transect. (Figs. 5 and 7; Table 2). The MS value lateral comparison among the sand layers was used regardless of the sand layer thickness because it is related to the mineral content rather than its width.

Although not all sand layers have the same characteristics, sand units S4, S5, S6, S7, S8, S9, and S10 can be considered as clear marine-origin events, based on attributes such as landward thinning, erosive basal contacts, presence of diatoms of marine species, landward decrease in magnetic susceptibility value, upward finning, and glauconite occurrence (Table 2). Contrastingly, sand units S1, S2, and S3 lack any such evidence; they are not related to marine-origin events. Although the lack of marine evidence does not necessarily indicate a non-marine origin (Goff and Chagué-Goff 2012), its relationship to a tsunami event is weaker than that of the other sand units. Suppose a marine origin is assumed for sand units S1, S2, and S3. In this case, one possible explanation is that they were deposited close to the bore front, where the horizontal velocity was high, and the flow was considerably more turbulent. Therefore, the flow conditions only allow reduced sediment content, typically represented in mica flakes and clay minerals (Yoshii et al. 2017). Consequently, the remaining weak wave led to the deposition of very thin and extent-limited sand layers that were highly susceptible to leaching, weathering, and poor preservation of marinerelated evidence.

Carbonate dissolution and XRD demonstrated that the positive calcium response to sand layers on ITRAX was related to the plagioclase content rather than the marine origin. The high presence of calcic plagioclase in the XRD results explains the calcium pattern in the ITRAX results (Appendix 1). Even though small quantities of carbonate were obtained in some sand layers (< $0.3 \%$ ) (Table 2), such values can be related to analytical error instead of real mineral content.

The presence of freshwater species related to the sand layers, mixed with marine species, can elucidate the reworking of marine provenance sediments with terrestrial material. Due to the minor thickness of the sand layers, it was not possible to determine whether the position of the marine species was related to a specific stratigraphic level. On the other hand, S8 exhibits that the marine diatoms are located in the base and top of the layer. This can be related to the increased mixing of marine and terrestrial materials during the progression and regression of the wave, in which the addition of in situ material is enhanced. Such behavior is not unusual because the background sedimentary environment is related to a marsh, where entrainment of freshwater species included in terrestrial sediments is expected. In addition, freshwater diatom species have been previously reported in the lithological units surrounding the study area (Kamada et al. 1991).

The grain size analysis was not entirely conclusive for inferring a marine origin. For instance, the grain size of the coarsest portion of the sand layers S4, S6, S7, S8, and S9 at $\mathrm{H03}$ was finer than that at $\mathrm{H02}$ (100 m seaward of H03). Horizontal changes in the grain size of the coarsest portion of the sand were not evident between $\mathrm{H} 03$ and $\mathrm{H} 04$, except for the sand layer S4. Thus, landward fining was not convincing among the core samples. This may be related to several factors, such as the particle size analysis performed with a small amount of sample, approximately $0.5 \mathrm{~g}$ each, the number of core samples is limited, and particularly because the changes in grain size are slight. F or instance, when comparing the maximum extent of the sand layer S8, approximately $200 \mathrm{~m}$ (Fig. 1 and Fig. 3b), to the number of core samples analyzed by grain size, it is not precise to assert that the sand layer is reducing landward grain size. Although the laser diffraction method offers high resolution, reliability, and reproductivity (Shimadzu 2012), the number of samples limits the quality of the results and increases the expected error for interpretation.

On the other hand, regarding sample preparation, sample homogenization using a spatula after organic matter dissolution may not be enough for sample disaggregation, which could leave some particle aggregates that could mislead the measurement. Thus, to improve the precision of the results, it is desirable to increase the sample volume and the number of sample measurements. This reduces systematic errors.

Page $12 / 28$ 
The sand layers, S5, S6, S7, and S8 exhibit slight or no lateral change in the probabilistic distributions of the grain size. On the other hand, S4, S9, and S10 show a remarkable variation from sand at $\mathrm{H} 02$ to mud at $\mathrm{H04}$. Interestingly, although $\mathrm{S} 5$ and S8 are the thickest sand layers and exhibit the maximum landward extent, the landward decrease in the mode value is not significant. This can be explained by the homogeneity in the source's grain size or greater flow speed and depth for the distance between H04 and H02, which is only $200 \mathrm{~m}$ (Fig. 3). However, some sedimentary characteristics can be observed in the grain-size probabilistic distributions, which fluctuate along with the sand layer showing the particles' behavior when they settle down. In sand layers, such as $\mathrm{S} 5$ in $\mathrm{H02}$ and S8b in $\mathrm{H02}$ from the middle to the upper part, and S8 in $\mathrm{H} 03$, in addition to upward fining, kurtosis tends to be reduced, and skewness tends to rise owing to a lower grain selection (Fig. 7). On the other hand, in S4 in H02 and S8 in H02 from S8a up to the middle of S8b, kurtosis and skewness behave oppositely, suggesting upward higher grain segregation. As described previously, some distribution curves exhibit multimodal distribution due to the mixing of sand-mud or sand-granules mixing. Coarser particles exhibiting negative phi values in a secondary mode peak are composed of rounded pumice grains and are distributed mostly towards the base and top of the layer (S5 in H02 and S8 in H02), and further inland (S5 and S8 in H04) (Fig. 7, Table 2). This can be explained by vertical sediment stratification by density during sediment transport in the inundation flow and differences in particle settling velocity.

In the mud layer interbedded with S9, the rip-up clast was derived from the mud layer below S9a. The front (Fig. 4c) and lateral (Fig. 4b) views expose differences in axial lengths, which points out the possible transport direction perpendicular to the a-axis; hence, perpendicular to the coastline. In the CT images from cores $\mathrm{H02}, \mathrm{H03}$, and $\mathrm{H0} 4$ (Fig. 4), units S6, S9, and S10 exhibit a remarkable landward decrease in thickness. In addition to the landward decrease in magnetic susceptibility (Fig. 5), landward thinning reflects the progressive reduction in energy and flow capacity during inundation from the sea (Fig. 4).

The lateral variation of MS in S7 is also different, with a maximum in the middle section of the transect (Fig. 5). As high values of magnetic susceptibility can be associated with high-energy environments (Černý et al. 2016), it is possible to suggest a flow velocity peak reached at that point. Even though the inverse grading is observed in $\mathrm{S7}$, diatom evidence points to its marine origin.

As mentioned before, Velasco et al. (2019) compared the inundation capacity of both storms and tsunamis in the area of this study by means of numerical modeling using the present-day topography without coastal engineered dikes. For the storm calculation, extreme parameters were utilized for a cyclone, which is unrealistic for Hachinohe because the trajectory of the storm was NE to SW (counter-clockwise), opposite to the expected Coriolis-induced SW to NE direction. Even under such extreme boundary conditions, the storm surge could not inundate and deposit sediments on areas higher than $3 \mathrm{~m}$ in elevation (Fig. 2a). For the tsunami surge, under the source parameters of the 2011 Tohoku-oki event, the calculated wave was capable of reaching the $5 \mathrm{~m}$-uplifted terrace (Fig. 2b). Therefore, closer or more potent tsunami sources are capable of inundating the study area further inland.

As will be described in the environment reconstruction section (see the discussion section in the body text), the sedimentation rate is constant from 5500 cal BP to 2000 cal BP, indicating that the sedimentary environment is associated with tectonic stability (Fig. 15). Hence, large vertical crustal movements did not occur, and the paleosurface in which the $\mathrm{S} 10$ event was settled was located approximately $1.7 \mathrm{~m}$ under the current topography (Fig. 3). The sand units identified as marine origin (i.e., S4, S5, S6, S7, S8, S9, and S10) were deposited on the exclusive tsunami domain zone, that is, areas above three-meters-high unaffected by the storm's influence (Fig. 3). Thus, the sand layers can be categorized as a result of the tsunami surges.

\subsection{Sedimentation processes}

\subsubsection{Implications from ITRAX and CT data}

The CT profile displayed bulk density changes associated with landward thickness reduction, packing, and grading (Figs. 4 and 7). Likewise, ITRAX-pattern analysis is significant not only for geochemical characterization but also for sedimentological analysis by showing elemental changes related to the clastic composition variation (Fig. 6 and Appendices 3, 4, and 5). Such trend changes in the sand layers exhibit a close relationship between the elemental pattern and changes in grain size, packing, and composition (Figs. 4, 6, and 7 and Appendices 3, 4, and 5). As the mud is mixed into the sand layer, the clastic signal (i.e., sand fraction) decreases proportionally with the sorting reduction and composition change (Fig. 7). Thus, the upward trend of the decrease or increase in $\mathrm{Ca}$ and Sr patterns in the sand layers can be associated with the sand-mud ratio change, respectively. As these two elements (Ca and Sr) have similar atomic properties, they can easily replace each other in the lattice (Nichols 2009) and can be related to the same origin. In addition, changes in Ti display variations in the content of heavy minerals (Arnaud et al. 2015) within sandy deposits, reflecting the density-gradation by a decrease in the particle settling velocity, due to the landward change in MS. Similarly, Rb is related to the mica content (Mills 1964), and these phyllosilicates have low density and low settling velocity. Its deposition takes place in the last lapse of the flow, increasing upward along with an increase in the mud portion.

Ta has high values in the peaty-mud layers because it tends to be dissolved by weathering and concentrated in the latest phases of fluvial sediment transport, depositing as mud on floodplains (Parker and Fleischer 1968; Fricke and Heilig 2006). Thus, Ca/Ta represents the subtraction of the mud content from the total $\mathrm{Ca}$ (i.e., plagioclase), which means that this ratio reflects the relative siliciclastic content along with the sediment core sample and its trend variation. As depicted by the rows in Fig. 6 and Appendices 3 and 4, when the Ca/Ta value decreases, the grain size and packing also decrease (Figs. 4 and 7). Consequently, the $\mathrm{Ca} /$ Ta pattern mimicked the relative grainsize and packing change. Ta was also helpful for normalizing the elements used in the LDA. As mentioned above, it is closely related to mud (Fig. 6 and Appendices 3, 4, and 5), and it can be considered relatively homogeneous and abundant in the core samples. Thus, it serves as a reference for the comparison of the elements related to the sand layers.

On the other hand, CT imagery suggested a rapid landward reduction in sand content and density via a reduction in color intensity in units S8 and S5.

\subsubsection{Implications from grain-size data}

Although the grain size analysis results are not sufficient for inferring a marine origin, it is still helpful to understand the sedimentary process. The inverse grading appeared in S7 and at the base of S8, both in H02 (Fig. 7). Three different mechanisms can explain this phenomenon. Firstly, Sohn (1997) described

Page $13 / 28$ 
the traction-carpet model as a result of a bivariant velocity profile, which results in upward coarsening along with an increase in velocity. Such a model has been developed based on turbidites and hyperconcentrated flow deposits (Sohn 1997), as well as previous paleotsunami studies (e.g., Moore et al. 2011; Minoura et al. 2013). Secondly, Yoshii et al. (2017) proposed that the inverse grading at the base of the deposit may be related to processes such as kinetic sieving, geometrical sieving, and spatial differences in flow speed (e.g., Middleton 1970; Kneller and Branney 1995; Dasgupta and Manna 2011), rather than traction- carpet sedimentation. Thirdly, Naruse et al. (2012) assumed velocity changes with time, including acceleration and deceleration cycles, which induce upward coarsening and fining, respectively, and are divided by an internal erosion surface (IES). The IES can be defined as the sedimentary truncation generated by the maximum shear velocity.

We interpreted the boundary between S8a and S8b as an IES (Fig. 4). Thus, both S8a and S8b corresponded to the same run-up event and represent a flow cycle of acceleration-deceleration, respectively. The presence of the two subunits in $\mathrm{H} 02$ can be explained by the reduction in internal sedimentary units along with landward thinning (Naruse et al. 2012).

All three explanations fit the inverse grading sedimentation style. Although Sohn's model employs a logarithmic profile of flow velocity and its increase with depth reduction and Naruse's model assumes velocity and acceleration changes with time, Yoshii's model includes geometrical properties. One does not necessarily exclude the other. In that sense, during the acceleration phase, a traction-carpet sedimentation style can be developed to generate inverse grading, such as in S8a. Undoubtedly, it is necessary to deepen the understanding of inverse-grading deposits in tsunami events.

Based on the sedimentological characteristics of the sand layers, it is possible to classify them into three types of sedimentation: (1) normal grading with fast landward sediment run-out, marked by a strong landward grain size change from sand to mud and landward thinning (S4, S9, and S10); (2) massive sands with slight vertical and lateral changes (S6 and S7), and (3) normal grading with thicker and broader sediment deposition (S5 and S8). Such settling can be related to three aspects: first, the sediment-source distribution and availability, which vary seasonally in the shoreface (Dean and Dalrymple 2004); second, the paleosurface formed by successive ponds that cause a rapid run out of the sediment by a rapid decay in the sediment transport capacity of the wave; and third, the surge's energy is controlled by the source magnitude and distance.

\subsection{Sedimentary environment}

GPR imagery displayed the basal and top boundaries that limit the peaty-mud-sand-event sequence, characterized as undulating paleosurfaces (Fig. 16). The brackish diatom species included in the peat-mud sediment depict a sedimentary environment of wetlands controlled by the influence of brackish water and anoxic regimes. These two features indicate that the sedimentary environment corresponds to a marsh complex formed by sequential ponds (Fig. 16). Such a setting not only controls the transport and deposition of organic-rich mud sediments, but also the maximum extent of the sand layers while restricting the progression of inundation.

Bioturbation intensification and appearance/disappearance of diatom species after sand layers S5 and S8 indicate sudden environmental changes (Fig. 4 and 10) (Dixit et al. 1992). Such alterations can be related either to the impact of extreme events on the local ecosystem or the progressive reduction in the water sheet thickness, hence increasing oxygen content and, consequently, bioturbation (Dixit et al. 1992; Nichols 2009).

Based on the ${ }^{14} \mathrm{C}$ dating results, the marsh environment possessed a constant sedimentation rate of approximately $82 \mathrm{~mm} / \mathrm{kyr}$. As the net thickness of the peaty-mud deposited from $\sim 5500 \mathrm{BP}$ to $\sim 2000 \mathrm{BP}$ is approximately $20 \mathrm{~cm}$, it represents the total sediment accumulated due to coupling between the sediment supply and tectonic subsidence between the top of S2 and the base of S10 (Fig. 13). The linear trend of the sedimentation rate coupled with the diatom assemblage suggests that neither significant nor strong tectonic movements were recorded. As seen in Sawai et al. (2012), diatom sensibility to environmental changes would allow the identification of crustal uplift or subsidence; however, this is not the case for the study area.

Regarding the To-a and To-cu thicknesses, it is possible that the thick layers were generated not only by an initial ash fallout but also by an ensuing lahar or pyroclastic flow derived from the Oirsase River, which directly drains towards the Towada caldera. In the same way, the sand layers S1, S2, and S3 can be associated with possible river floods, as the survey area is bounded by the Oirsase and Gonohe rivers.

\subsection{Recurrence interval and regional correlation of tsunami events}

The calibrated ${ }^{14} \mathrm{C}$ results exhibited an average recurrence interval of 545 to 1240 years $(2 \sigma)$ for all sand layers (Table 5), during the period between 1200 and $5500 \mathrm{yr}$ BP. However, the lack of marine evidence indicates that sand layers S1, S2, and S3 cannot be directly correlated to tsunami events, and their inclusion

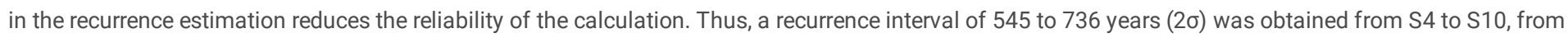
$\sim 2700$ to $\sim 5500 \mathrm{yr}$ BP. This does not imply that no tsunami affected the Hachinohe area between $\sim 1200$ and $\sim 2700 \mathrm{yr}$ BP. Instead, it suggests that there was no tsunami evidence recorded or the geological conditions for such time were different and left tsunami evidence without a clear marine imprint.

On the coast of Misawa city, Tanigawa et al. (2014) identified a tsunami deposit formed from 2900 to 4800 cal BP, which can be broadly correlated with events S4, S5, S6, S7, S8, and S9 in the present study (Fig. 15). To the south, tsunami events from Hachinohe can be correlated with events found by Takada et al. (2016) in Harashinai in Hirono Town (Fig. 15). Such chronological correlations lack sufficient accuracy owing to the error ranges of the calibrated ${ }^{14} \mathrm{C}$ ages.

Based on an exclusive chronological correlation, the recurrence interval inferred from paleotsunami deposits in Hachinohe is slightly shorter than that

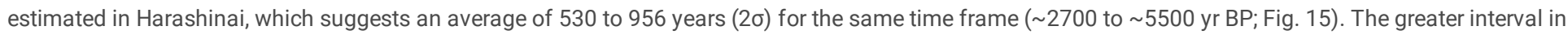
Harashinai can be related to two factors: first, the confidence intervals $(2 \sigma)$ of the probabilistic ages for TSb8, TSb9, and TSb10 are considerably broad, which causes an equally broad probabilistic distribution for the calculated recurrence; second, Harashinai and Hachinohe face both trenches at different angles and at different latitudes. This means that evidence from Hachinohe can be related to the activity of the Kuril and Japan trenches and the their junction, while the 
evidence recorded in Harashinai can be primarily related to the activity of the Japan Trench (e.g., Figure 7 in Tetsuka et al., 2020). Such geological records and recurrence intervals reaffirm the importance of Hachinohe as a suitable site for paleotsunami research.

To improve temporal correlations and recurrence estimation, it is imperative to increase the precision of the deposition ages by conducting detailed studies at every site. Such studies must include rip-up clast dating and high-resolution systematic dating, coupled with a Bayesian analysis (Ishizawa et al. 2017; Ishizawa et al. 2018; Ishizawa et al. 2020). Complementarily, the application of optically stimulated luminescence (OSL) can contribute to constraining deposition ages and as a complementary source-discrimination proxy (López et al. 2018). In addition, numerical modeling of the tsunami sources will improve our understanding of the size of tsunami events that are capable of inundating the tsunami deposit sites examined here (e.g., Figure 7 in Tetsuka et al., 2020).

\section{Conclusions}

In this study, we carried out a geological investigation of paleotsunami in Hachinohe, Aomori Prefecture, northern Japan, to reconstruct the recurrence interval of tsunamis that left sedimentary evidence on the uplifted marine terrace. Numerical modeling allowed us to determine the best possible survey point and rule out the possibility of storms as a genetic factor. By implementing a multiproxy analysis, we identified the provenance of the sand layers and their marine imprints. Sedimentological analysis indicated that three types of depositional settings existed among the sand layers: (1) normal grading with fast landward sediment run-out, marked by a strong landward grain size change from sand to mud and landward thinning (S4, S9, and S10); (2) massive sands with slight vertical and lateral changes (S6 and S7), and (3) normal grading with thicker and broader sediment deposition (S5 and S8). Such sedimentary differences can be related to sediment-source distribution and availability, the paleosurface formed by successive ponds and vegetation that causes a quick run out of the sediment by a rapid decay in the sediment transport capacity of the wave, and the surge's energy controlled by the source magnitude and distance. As a result, we identified seven sand layers (S4 to S10) as tsunami origin with a recurrence interval of 545 to 736 years (2б), from 5500 BP to 2700 BP. Further paleotsunami studies in the Shimokita Peninsula must be conducted to reduce uncertainty in the chronological correlation, understand the maximum spatial extent of the paleotsunami deposits, and constrain possible sources.

\section{Abbreviations}

CT, computed tomography

GPR, ground penetrating radar

LDA, linear component analysis

PCA, principal component analysis

To-a, Towada-a

To-cu, Towada-cu

$\mathrm{XRF}$, X-ray fluorescence

$X R D, X$-ray diffraction. MS

magnetic susceptibility

\section{Declarations \\ Declarations}

\section{Competing interests}

The authors declare that they have no competing interest.

\section{Funding}

This research was supported by JSPS KAKENHI Grant Numbers 17H02971 and 18H03820, by the International Research Institute of Disaster Science (IRIDeS), and by the International Joint Graduate Program in Earth and Environmental Sciences (GP-EES) of Tohoku University.

\section{Authors' contributions}

$\square$ All authors accompanied field surveys, collected samples, and participated in discussions during the research. Complementarily, EVs performed the experiments and wrote the manuscript. KG proposed, conceived, and designed the study. TS conducted preliminary research and collected samples for dating on the core sample Ha8. TC conducted diatom analysis. All authors read and approved the final manuscript.

\section{Acknowledgements}

GCT images and ITRAX analyses were conducted at the Center for Advanced Marine Core Research at Kochi University. We particularly thank the landowners for their permission to conduct the field surveys. We would like to thank K. Nakamura and T. Ishizawa, and M. Watanabe for their assistance during the field trip, during laboratory analysis, and for his collaboration with the numerical simulations, respectively. 


\section{References}

1. Abe T, Goto K, Sugawara D (2012) Relationship between the maximum extent of tsunami sand and the inundation limit of the 2011 Tohoku-oki tsunami on the Sendai Plain, Japan. Sediment Geol 282:142-150. https://doi.org/10.1016/j.sedgeo.2012.05.004

2. Akiba F (1986) Middle Miocene to Quaternary diatom biostratigraphy in the Nankai Trough and Japan Trench, and modified Lower Miocene through Quaternary diatom zones for middle-to-high latitudes of the North Pacific. Initial reports Deep sea Drill Proj 87:393-480

3. Albertao GA, Bourgeois J, Cita MB, Dawson A, Fujino S, Fujiwara O, Goto K, Helsey CE, Higman B, Ichihara T, Imamura F, Jarupongsakul T, Kamataki T, Keating BH, Keerthi N, Marini F, Martins PP, Matsui T, Minoura K, Murayama M, Nanayama F, Naruse H, Nishimura Y, Ruangrassamee A, Scheffers AM, Shiki T, Stwewart I, Sugawara D, Supharatid S, Suphawajruksakul A, Tachibana T, Tada R, Tajika E, Tsuji Y, Wanik M, Yamazaki T (2008) Tsunamiites Features and Implications, First. Elsevier, Amsterdam

4. Andrew A, Szczuciński W, Nishimura Y (2012) Geochemical signatures up to the maximum inundation of the 2011 Tohoku-oki tsunami - Implications for the 869 AD Jogan and other palaeotsunamis. Sediment Geol 282:65-77. https://doi.org/10.1016/J.SEDGE0.2012.05.021

5. Arnaud F, Atahan P, Ausili A, Bakke J, Balascio N, Bergamin L, Bertrand S, Berube F, Bloemsma MR, Boyle JF, Bradley RS, Brauer A, Brewer P, Brown ET, Brummer G, Bull JM, Comas MC, Chagué-Goff C, Chiverrell R, Cohen D, Cotterill CJ, Cremer J., Croudance IW, Cuven S, Davies SJ, Dix JK, Dulski P, Enters D, Fortin D, Fierro D, Francus F, Gadd P, Giosan L, Goralewski J, Grove GA (2015) Micro-XRF Studies of Sediment Cores: Applications of a non-destructive tool for the environmental sciences. Springer

6. Bishop T (2016) The Core-Scanning $\propto$ XRF Table of the Elements. 1

7. Blott SJ, Pye K (2001) GRADISTAT: a grain size distribution and statistics package for the analysis of unconsolidated sediments. Earth Surf Process Landforms 26(C):1237-1248. https://doi.org/10.1016/S0167-5648(08)70015-7

8. Bronk Ramsey C (2017) Methods for Summarizing Radiocarbon Datasets. Radiocarbon 59(6):1809-1833. https://doi.org/10.1017/RDC.2017.108

9. Castillo-Aja R, Ramírez-Herrera MT, Machain-Castillo ML, Goguitchaichvili A, Cejudo R (2019) Sedimentary and microfossil imprint from historical earthquakes and tsunamis, Jalisco coast, Mexican subduction. Mar Geol 407(November 2017):32-43. https://doi.org/10.1016/j.margeo.2018.10.004

10. Černý J, Ramírez-Herrera MT, Bógalo MF, Goguitchaichvili A, Castillo-Aja R, Morales J, Sanchez-Cabeza JA, Ruiz-Fernández AC (2016) Magnetic record of extreme marine inundation events at Las Salinas site, Jalisco, Mexican Pacific coast. Int Geol Rev 58(3):342-357. https://doi.org/10.1080/00206814.2015.1075230

11. Chagué-Goff C, Chan JCH, Goff J, Gadd P (2016) Late Holocene record of environmental changes, cyclones and tsunamis in a coastal lake, Mangaia, Cook Islands. Isl Arc 25(5):333-349. https://doi.org/10.1111/iar.12153

12. Chagué-Goff C, Goff J, Wong HKY, Cisternas M (2015) Insights from geochemistry and diatoms to characterise a tsunami's deposit and maximum inundation limit. Mar Geol 359:22-34. https://doi.org/10.1016/j.margeo.2014.11.009

13. Chagué-Goff C, Szczuciński W, Shinozaki T (2017) Applications of geochemistry in tsunami research: A review. Earth-Science Rev 165:203-244. https://doi.org/10.1016/j.earscirev.2016.12.003

14. Chawchai S, Kylander ME, Chabangborn A, Löwemark L, Wohlfarth B (2016) Testing commonly used X-ray fluorescence core scanning-based proxies for organic-rich lake sediments and peat. Boreas 45(1):180-189. https://doi.org/10.1111/bor.12145

15. Cisternas M, Garrett E, Wesson R, Dura T, Ely LL (2018) Unusual geologic evidence of coeval seismic shaking and tsunamis shows variability in earthquake size and recurrence in the area of the giant 1960 Chile earthquake. Mar Geol 396(February):54-66. https://doi.org/10.1016/j.margeo.2018.01.005

16. Costa PJM, Costas S, González-Villanueva R, Oliveira MA, Roelvink D, Andrade C, Freitas MC, Cunha PP, Martins A, Buylaert JP, Murray A (2016) How did the AD 1755 tsunami impact on sand barriers across the southern coast of Portugal? Geomorphology 268:296-311. https://doi.org/10.1016/j.geomorph.2016.06.019

17. Croudace IW, Rindby A, Rothwell RG (2006) ITRAX: Description and evaluation of a new multi-function X-ray core scanner. Geol Soc Spec Publ $267: 51-63$. https://doi.org/10.1144/GSL.SP.2006.267.01.04

18. Dasgupta P, Manna P (2011) Geometrical mechanism of inverse grading in grain-flow deposits: An experimental revelation. Earth-Science Rev 104(13):186-198. https://doi.org/10.1016/j.earscirev.2010.10.002

19. Dean R, Dalrymple R (2004) Coastal Process with engineering applications, First Edit. Cambridge University Press

20. Dixit SS, Smol JP, Kingston JC, Charles DF (1992) Diatoms: Powerful Indicators of Environmental Change. Environ Sci Technol 26(1):22-33. https://doi.org/10.1021/es00025a002

21. Fricke G, Heilig K (2006) Ta-Tantalum. In: Geochemical atlas of Europe. Part 2. Geological Survey of Finland

22. Gerlach RW, Dobb DE, Raab GA, Nocerino JM (2002) Gy sampling theory in environmental studies. 1. Assessing soil splitting protocols. J Chemom 16(7):321-328. https://doi.org/10.1002/cem.705

23. Goff J, Chagué-Goff C (2012) A review of palaeo-tsunamis for the Christchurch region, New Zealand. Quat Sci Rev 57:136-156. https://doi.org/10.1016/j.quascirev.2012.10.004

24. Goff J, Chagué-Goff C, Nichol S, Jaffe B, Dominey-Howes D (2012) Progress in palaeotsunami research. Sediment Geol 243-244:70-88. https://doi.org/10.1016/j.sedgeo.2011.11.002

25. Goto K, Chagué-Goff C, Goff J, Jaffe B (2012) The future of tsunami research following the 2011 Tohoku-oki event. Sediment Geol 282:1-13. https://doi.org/10.1016/j.sedgeo.2012.08.003 
26. Goto K, Ikehara K, Goff J, Chagué-Goff C, Jaffe B (2014) The 2011 Tohoku-oki tsunami - Three years on. Mar Geol 358:2-11. https://doi.org/10.1016/j.margeo.2014.08.008

27. Goto T, Satake K, Sugai T, Ishibe T, Harada T, Gusman AR (2019) Tsunami history over the past 2000 years on the Sanriku coast, Japan, determined using gravel deposits to estimate tsunami inundation behavior. Sediment Geol 382:85-102. https://doi.org/10.1016/j.sedgeo.2019.01.001

28. Goto T, Satake K, Sugai T, Ishibe T, Harada T, Murotani S (2015) Historical tsunami and storm deposits during the last five centuries on the Sanriku coast, Japan. Mar Geol 367:105-117. https://doi.org/10.1016/j.margeo.2015.05.009

29. Hatori T (1975) Tsunami magnitude and wave source regions of historical Sanriku tsunamis in northeast Japan. Bull Earthq Res Inst 50:397-414

30. Hirakawa K, Nakamura Y, Nishimura Y (2005) Mega-tsunamis since last 6500 years along the Pacific coast of Hokkaido. Chikyu Mon. Extra Ed. 49:173180 (in Japanese)

31. Huggett JM (2013) Minerals: Glauconites and Green Clays. Elsevier Inc.

32. Ide S, Aochi H (2013) Historical seismicity and dynamic rupture process of the 2011 Tohoku-Oki earthquake. Tectonophysics $600: 1-13$. https://doi.org/10.1016/j.tecto.2012.10.018

33. Imaizumi T, Ishiyama T, Haraguchi T, Miyauchi T, Goto H, Shimazaki K (2010) Research of the earthquake history based on the survey of tsunami deposits. Compr. Rep. Focus. Res. Off-Miyagi Earthquakes 152-185 (in Japanese)

34. Inoue T, Goto K, Nishimura Y, Watanabe M, lijima Y, Sugawara D (2017) Paleo-tsunami history along the northern Japan Trench: evidence from Noda Village, northern Sanriku coast, Japan. Prog Earth Planet Sci 4(1):1-15. https://doi.org/10.1186/s40645-017-0158-1

35. loki K, Tanioka Y (2016) Re-estimated fault model of the 17th century great earthquake off Hokkaido using tsunami deposit data. Earth Planet Sci Lett 433:133-138. https://doi.org/10.1016/j.epsl.2015.10.009

36. Ishimura D (2017) Re-examination of the age of historical and paleo-tsunami deposits at Koyadori on the Sanriku Coast, Northeast Japan. Geosci Lett 4(1). https://doi.org/10.1186/s40562-017-0077-4

37. Ishimura D, Miyauchi T (2015) Historical and paleo-tsunami deposits during the last 4000 years and their correlations with historical tsunami events in Koyadori on the Sanriku Coast, northeastern Japan. Prog Earth Planet Sci 2(1):1-18. https://doi.org/10.1186/s40645-015-0047-4

38. Ishizawa T, Goto K, Yokoyama Y, Goff J (2020) Dating tsunami deposits: Present knowledge and challenges. Earth-Science Rev 200(October 2019). https://doi.org/10.1016/j.earscirev.2019.102971

39. Ishizawa T, Goto K, Yokoyama Y, Miyairi Y (2019) Non-destructive analyses to determine appropriate stratigraphic level for dating of tsunami deposits. Mar Geol 412:19-26. https://doi.org/10.1016/j.margeo.2019.02.009

40. Ishizawa T, Goto K, Yokoyama Y, Miyairi Y, Sawada C, Nishimura Y, Sugawara D (2017) Sequential radiocarbon measurement of bulk peat for highprecision dating of tsunami deposits. Quat Geochronol 41:202-210. https://doi.org/10.1016/j.quageo.2017.05.003

41. Ishizawa T, Goto K, Yokoyama Y, Miyairi Y, Sawada C, Takada K (2018) Reducing the age range of tsunami deposits by $14 \mathrm{C}$ dating of rip-up clasts. Sediment Geol 364:334-341. https://doi.org/10.1016/j.sedgeo.2017.09.008

42. Jaffe B, Goto K, Sugawara D, Gelfenbaum G, La Selle SP (2016) Uncertainty in tsunami sediment transport modeling. J Disaster Res 11(4):647-661. https://doi.org/10.20965/jdr.2016.p0647

43. Jagodziński R, Sternal B, Szczuciński W, Lorenc S (2009) Heavy minerals in 2004 tsunami deposits on Kho Khao Island, Thailand. Polish J Environ Stud 18(1):103-110

44. Judd K, Chagué-Goff C, Goff J, Gadd P, Zawadzki A, Fierro D (2017) Multi-proxy evidence for small historical tsunamis leaving little or no sedimentary record. Mar Geol 385:204-215. https://doi.org/10.1016/j.margeo.2017.01.002

45. Kain CL, Gomez C, Hart DE, Chagué-Goff C, Goff J (2015) Analysis of environmental controls on tsunami deposit texture. Mar Geol 368:1-14. https://doi.org/10.1016/j.margeo.2015.06.011

46. Kamada K, Hata M, Kubo K, Sakamoto T (1991) Geological map of Hachinohe, 1:200.000

47. Kneller BC, Branney MJ (1995) Sustained high-density turbidity currents and the deposition of thick massive sands. Sedimentology 42(4):607-616. https://doi.org/10.1111/j.1365-3091.1995.tb00395.x

48. Kobayashi H, Idei M, Mayama S, Nagumo T, Osada KH (2006) Kobayasi's Atlas of Japanese Diatoms Based on Electron Microscopy, 1 (in Japa. Unhida Rokakuho, Tokyo

49. Krammer K, Lange-Bertalot H (1986) Bacillariophyceae 1. Teil: Naviculaceae. Süßwasserflora von Mitteleuropa. Gustave Fischer Verlag, Stuttgart

50. Krammer K, Lange-Bertalot H (1988) Bacillariophyceae 2. Teil: Bacillariaceae, Epithemiaceae, Sururellaceae. Süßwasserflora von Mitteleuropa $2 / 2$. Gustave Fischer Verlag, Stuttgart

51. Krammer K, Lange-Bertalot H (1991a) Bacillariophyceae 3. Teil: Centrales, Fragilariaceae, Eunotiaceae. Süßwasserflora von Mitteleuropa 2/3. Gustave Fischer Verlag, Stuttgart

52. Krammer K, Lange-Bertalot H (1991b) Bacillariophyceae 4. Teil: Achnanthaceae, Kritische Erganzungenzu Navicula (Lineolatae) und Gomphonema. Süßwasserflora von Mitteleuropa 2/4. Gustave Fischer Verlag, Stuttgart

53. Kudo T, Sasaki H (2007) High-precision chronology of eruptive products during postcaldera stage Towada volcano, Northeast Japan. J Geogr Zasshi) 116(5):653-663. https://doi.org/10.2320/materia.46.171

54. Lange-Bertalot H (1993) 85 Neue Taxa und über 100 weitere neu definierte Taxa ergänzend zur Süßwasserflora von Mitteleuropa. J. Cramer, Berlin, Stuttgart 
55. Lange-Bertalot H (2001) Navicula sensu stricto. 10 Genera separated from Navicula sensu lato. Frustulia Diatoms of Europe: diatoms of the European inland waters and comparable habitats. A.R.G. Gantner Verlag K.G., Ruggell

56. Lange-Bertalot H, Cavacini P, Tagliaventi N, Alfinito S (2003) Diatoms of Sardinia. Rare and 76 new species in rock pools and other ephemeral waters. A.R.G. Gantner Verlag K.G., Ruggell

57. Lange-Bertalot H, Genkal SI (1999) Diatoms from Siberia I -Islands in the Arctic Ocean (Yugorsky-Shar Strait) Diatomeen aus Siberien. I. Insel im Arktischen Ozean (Yugorsky-Shar Strait). Koeltz Scientific Books, Königstein

58. Lange-Bertalot H, Külbs K, Lauser T, Nörpel-Schempp M, Willmann M (1996) Dokumentation und Revision der von Georg Krasske beschriebenen Diatomeen-Taxa. Koeltz Scientific Books, Königstein

59. Lange-Bertalot H, Moser G (1994) Brachysira. Monographie der Gattung und Naviculadicta nov. gen. J. Cramer, Berlin, Stuttgart

60. Levkov Z, Krstic S, Metzeltin D, Nakov T (2007) Diatoms of Lake Prespa and Ohrid. About 500 taxa from ancient lake system. A.R.G. Gantner Verlag K.G., Ruggell

61. Levkov Z, Metzeltin D, Pavlov A (2003) Luticola and Luticolopsis, Diatoms of the European Inland. In: Waters and Comparable Habitats. A.R.G. Gantner Verlag K.G., Ruggell

62. Lienkaemper JJ, Ramsey CB (2009) OxCal: Versatile Tool for Developing Paleoearthquake Chronologies-A Primer. Seismol Res Lett 80(3):431-434. https://doi.org/10.1785/gssrl.80.3.431

63. López GI (2017) Grain Size Analysis. In: Gilbert AS (ed) Encyclopedia of Geoarchaeology. Springer, pp 341-348

64. López GI, Goodman-Tchernov BN, Porat N (2018) OSL over-dispersion: A pilot study for the characterisation of extreme events in the shallow marine realm. Sediment Geol 378:35-51. https://doi.org/10.1016/j.sedgeo.2018.09.002

65. Löwemark L, Bloemsma M, Croudace I, Daly JS, Edwards RJ, Francus P, Galloway JM, Gregory BRB, Steven Huang JJ, Jones AF, Kylander M, Luo Y, Maclachlan S, Ohlendorf C, Patterson RT, Pearce C, Profe J, Reinhardt EG, Stranne C, Tjallingii R, Turner JN (2019) Practical guidelines and recent advances in the Itrax XRF core-scanning procedure. Quat Int 514:16-29. https://doi.org/10.1016/j.quaint.2018.10.044

66. Machida H, Arai F (2003) Atlas of Tephra in and around Japan(revised edition). University of Tokyo Press

67. Mann DG, McDonald SM, Bayer MM, Droop SJM, Chepurnov VA, Loke RE, Ciobanu A, du Buf JMH (2004) The Sellaphora pupula species complex (Bacillariophyceae): morphometric analysis, ultrastructure and mating data provide evidence for five new species. Phycologia 43:459-482

68. Mees F, Swennen R, Van Geet M, Jacobs M (2003) Applications of X-ray Computed Tomography in the Geosciences (Geological Society Special Publication) (No. 215). Geol Soc London 2015(Special Publications):1-6

69. Middleton GVGV (1970) Experimental Studies Related to Problems of Flysch Sedimentation

70. Mills AA (1964) Rapid Analysis of Strontium and Rubidium in Minerals. Can J Chem 42(1):73-78. https://doi.org/10.1139/v64-012

71. Minoura K, Hirano S ichi, Yamada T (2013) Identification and possible recurrence of an oversized tsunami on the Pacific coast of northern Japan. Nat Hazards 68(2):631-643. https://doi.org/10.1007/s11069-013-0640-z

72. Minoura K, Nakaya S, Uchida M (1994) Tsunami deposits in a lacustrine sequence of the Sanriku coast, northeast Japan. Sediment Geol 89(1-2):25-31. https://doi.org/10.1016/0037-0738(94)90081-7

73. Miyauchi T, Plain KC, Miurayama T, Range OB, Hills S, Mountains K, N-s N, Block K, Block O (1987) Quaternary Tectonic Movements Northeast of the Japan Kamikita Coastal Plain ,. 60(1):1-19

74. Moore A, Goff J, McAdoo BG, Fritz HM, Gusman A, Kalligeris N, Kalsum K, Susanto A, Suteja D, Synolakis CE (2011) Sedimentary Deposits from the 17 July 2006 Western Java Tsunami, Indonesia: Use of Grain Size Analyses to Assess Tsunami Flow Depth, Speed, and Traction Carpet Characteristics. Pure Appl Geophys 168(11):1951-1961. https://doi.org/10.1007/s00024-011-0280-8

75. Moore D m., Reynolds RCJ (1999) X-ray Diffraction and the Identification and Analysis of Clay Minerals, New York. Oxford University Press

76. Moreira S, Costa PJM, Andrade C, Ponte Lira C, Freitas MC, Oliveira MA, Reichart GJ, Reichart GJ (2017) High resolution geochemical and grain-size analysis of the AD 1755 tsunami deposit: Insights into the inland extent and inundation phases. Mar Geol 390(April):94-105.

https://doi.org/10.1016/j.margeo.2017.04.007

77. Morton RA, Gelfenbaum G, Jaffe BE (2007) Physical criteria for distinguishing sandy tsunami and storm deposits using modern examples. Sediment Geol 200(3-4):184-207. https://doi.org/10.1016/j.sedgeo.2007.01.003

78. Nagai R, Kikuchi M, Yamanaka Y (2001) Comparative Study on the Source Processes of Recurrent Large Earthquakes in Sanriku-oki Region: the 1968 Toachi-oki Earthquake and the 1994 Sanriku-oki Earthquake. J Seismol Soc Japan 54(2):267-280

79. Nagumo T (2003) Taxonomic studies of the subgenus Amphora Cleve of the genus Amphora (Bacillariophyceae) in Japan. In: Bibliotheca Diatomologica. J. Cramer, Berlin, Stuttgart

80. Nakamura Y, Nishimura Y, Putra PS (2012) Local variation of inundation, sedimentary characteristics, and mineral assemblages of the 2011 Tohoku-oki tsunami on the Misawa coast, Aomori, Japan. Sediment Geol 282:216-227. https://doi.org/10.1016/j.sedgeo.2012.06.003

81. Nanayama F, Furukawa R, Shigeno K, Makino A, Soeda Y, Igarashi Y (2007) Nine unusually large tsunami deposits from the past 4000 years at Kiritappu marsh along the southern Kuril Trench. Sediment Geol 200(3-4):275-294. https://doi.org/10.1016/j.sedgeo.2007.01.008

82. Nanayama F, Satake K, Furukawa R, Shimokawa K, Atwater BF, Shigeno K, Yamaki S (2003) Unusually large earthquakes inferred from tsunami deposits along the Kuril trench. Nature 424(6949):660-663. https://doi.org/10.1038/nature01864

83. Nanayama F, Shigeno K, Miura K, Makino A, Furukawa R, Satake K, Saito K, Sagayama T, Nakagawa M (2002) Evaluation of tsunami inundation limits from distribution of event deposits along the Kuril subduction zone, eastern Hokkaido; comparison of the Tokachi and Nemuro-Kushiro coasts. Annu Rep

Page $18 / 28$ 
Act Fault Paleoearthquake Res 2(March):209-222

84. Naruse H, Arai K, Matsumoto D, Takahashi H, Yamashita S, Tanaka G, Murayama M (2012) Sedimentary features observed in the tsunami deposits at Rikuzentakata City. Sediment Geol 282:199-215. https://doi.org/10.1016/j.sedgeo.2012.08.012

85. Nichols G (2009) Sedimentology and Stratigraphy, Second. Wiley-Blackwell, Oxford

86. Niwa Y, Sugai T (2021) Millennial-scale vertical deformation of the Hachinohe coastal plain (NE Japan). Geomorphology :107835. https://doi.org/10.1016/j.geomorph.2021.107835

87. Ozawa S, Nishimura T, Suito H, Kobayashi T, Tobita M, Imakiire T (2011) Coseismic and postseismic slip of the 2011 magnitude-9 Tohoku-Oki earthquake. Nature 475(7356):373-376. https://doi.org/10.1038/nature10227

88. Paris R, Falvard S, Chagué C, Goff J, Etienne S, Doumalin P (2019) Sedimentary fabric characterised by X-ray tomography: A case-study from tsunami deposits on the Marquesas Islands, French Polynesia. Sedimentology. https://doi.org/10.1111/sed.12582

89. Parker RL, Fleischer M (1968) Geochemistry of Niobium and Tantalum. Geol Surv Prof Pap 612:41

90. Patrick RM, Reimer CW (1966) The diatoms of the United States, exclusive of Alaska and Hawaii

91. Ramírez-Herrera MT, Bógalo MF, Černý J, Goguitchaichvili A, Corona N, Machain ML, Edwards AC, Sosa S (2016) Historic and ancient tsunamis uncovered on the Jalisco-Colima Pacific coast, the Mexican subduction zone. Geomorphology 259:90-104. https://doi.org/10.1016/j.geomorph.2016.02.011

92. Rao CR, Govindaraju V (eds) (2013) Handbook of Statistics, Volume 31. Elsevier

93. Reichart E (1995) Die Diatomeen (Bacillariophyceae) in Ehrenbergs Material von Cayenne, Guyana Gallica (1843). Koeltz Scientific Books, Königstein

94. Reichart E (1999) Zur Revision der Gattung Gomphonema. Die Arten um G. affine/insigne, G. angustatum/micropus, G. acuminatum sowie gomphonemoide Diatomeen aus dem Oberoligozän in Böhmen., Annotated. A.R.G. Gantner Verlag K.G.

95. Reimer PJ, Bard E, Bayliss A, Beck WJ, Blackwell PG, Bronk Ramsey C, Buck CE, Cheng H, Edwards LR, Friedirich M, Gootes PM, Guilderson TP, Haflidaso H, Hajdas I, Hatte C, Heaton T, Hoffman DL, Hogg AG, Hughen KA, Kaiser KF, Kromer B, Manning SW, Niu M, Reimer RW, Richards DA, Scott EM, Southon JR, Staff RA, Turney CSM, van der Plicht J (2013) Intcal13 and Marine13 Radiocarbon Age Calibration Curves 0-50,000 Years Cal Bp. Radiocarbon 55(4):1869-1887. https://doi.org/10.1017/S0033822200048864

96. Renberg I (1990) A procedure for preparing large sets of diatom slides from sediment cores. J Paleolimnol 4(1):87-90. https://doi.org/10.1007/BF00208301

97. Sawai Y, Kamataki T, Shishikura M, Nasu H, Okamura Y, Satake K, Thomson KH, Matsumoto D, Fujii Y, Komatsubara J, Aung TT (2009) Aperiodic recurrence of geologically recorded tsunamis during the past 5500 years in eastern Hokkaido, Japan. J Geophys Res Solid Earth 114(1). https://doi.org/10.1029/2007JB005503

98. Sawai Y, Namegaya Y, Okamura Y, Satake K, Shishikura M (2012) Challenges of anticipating the 2011 Tohoku earthquake and tsunami using coastal geology. Geophys Res Lett 39(21):1-6. https://doi.org/10.1029/2012GL053692

99. Seno T (1978) Intraplate Seismicity in Tohoku and Hokkaido and Large Intraplate Earthquakes: A possibility of A Large Interplate Earthquake Off the Southern Sanriku Coast, Northern Japan. J Phys Earth 27:21-51. https://doi.org/https://doi.org/10.4294/jpe1952.27.21

100. Shimadzu (2012) Laser Diffraction Particle Size Analyzer SALD-2300. 20

101. Shinohara T, Goto K, Sugawara D (2017) Paleotsunami history in Hachinohe, Aomori. In: JpGU. pp 2-3

102. Shinozaki T, Fujino S, Ikehara M, Sawai Y, Tamura T, Goto K, Sugawara D, Abe T (2015a) Marine biomarkers deposited on coastal land by the 2011 Tohoku-oki tsunami. Nat Hazards 77(1):445-460. https://doi.org/10.1007/s11069-015-1598-9

103. Shinozaki T, Goto K, Fujino S, Sugawara D, Chiba T (2015b) Erosion of a paleo-tsunami record by the 2011 Tohoku-oki tsunami along the southern Sendai Plain. Mar Geol 369:127-136. https://doi.org/10.1016/j.margeo.2015.08.009

104. Shyu JBH, Tsai YL, Ota Y, Sawai Y, Kunz A (2019) Identification of extreme event deposits on the coastal Ilan Plain, northeastern Taiwan. Quat Int 503(August 2018):70-78. https://doi.org/10.1016/j.quaint.2018.08.012

105. Simonsen R (1987) Atlas and Catalogue of the Diatom Types of Friedrich Hustedt. J. Cramer, Berlin, Stuttgart

106. Sohn Y. (1997) On traction-carpet sedimentation. J Sediment Res 67:502-509

107. Sugawara D, Goto K, Imamura F, Matsumoto H, Minoura K (2012) Assessing the magnitude of the 869 Jogan tsunami using sedimentary deposits: Prediction and consequence of the 2011 Tohoku-oki tsunami. Sediment Geol 282:14-26. https://doi.org/10.1016/j.sedgeo.2012.08.001

108. Sugawara D, Minoura K, Imamura F (2008) Tsunamis and Tsunami Sedimentology. Elsevier B.V.

109. Szczuciński W, Pawłowska J, Lejzerowicz F, Nishimura Y, Kokociński M, Majewski W, Nakamura Y, Pawlowski J (2016) Ancient sedimentary DNA reveals past tsunami deposits. Mar Geol. https://doi.org/10.1016/j.margeo.2016.08.006

110. Takada K, Nakata T, Miyagi T, Haraguchi T, Nishitani Y (2002) Handy Geoslicer - New Soil Sampler for Quaternary Geologist. (in Japanese with abstract in English). Chisitsu News 12-18

111. Takada K, Shishikura M, Imai K, Ebina Y, Goto K, Koshiya shin, Yamamoto H, Igarashi A, Ichihara T, Kinoshita H, Ikeda T, Iwate Prefecture Government DD

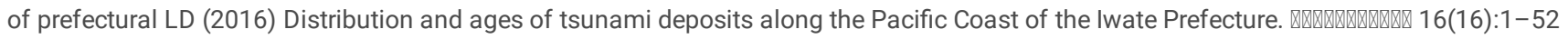

112. Tanaka H, Nagumo T (2004) Pliocaenicus nipponicus sp. nov., a new freshwater fossil diatom from central Japan. Diatom 20:105-111

113. Tanigawa K, Sawai Y, Shishikura M, Fujiwara O, Namegaya Y (2014a) Event deposits on the Pacific coast of Misawa, Aomori Prefecture, northern Japan. Quat Res 53(1):55-62. https://doi.org/10.4116/jaqua.53.55

114. Tanigawa K, Sawai Y, Shishikura M, Namegaya Y, Matsumoto D (2014b) Geological evidence for an unusually large tsunami on the Pacific coast of Aomori, northern Japan. J Quat Sci 29(2):200-208. https://doi.org/10.1002/jqs.2690

Page $19 / 28$ 
115. Tanioka Y, Satake K (1996) Fault parameters of the 1896 Sanriku tsunami earthquake estimated from tsunami numerical modeling. Geophys Res Lett 23(13):1549-1552

116. Tetsuka H, Goto K, Ebina Y, Sugawara D, Ishizawa T (2020) Historical and geological evidence for the seventeenth-century tsunamis along Kuril and Japan trenches: implications for the origin of the AD 1611 Keicho earthquake and tsunami, and for the probable future risk potential. Geol Soc London, Spec Publ 501(28):SP501-2019-60. https://doi.org/10.1144/sp501-2019-60

117. Trauth MH (2015) MATLAB ® Recipes for Earth Sciences, Second Edi. Springer

118. Uchida N, Kirby SH, Umino N, Hino R, Kazakami T (2016) The great 1933 Sanriku-oki earthquake: reappraisal of the main shock and its aftershocks and implications for its tsunami using regional tsunami and seismic data. :1619-1633. https://doi.org/10.1093/gji/ggw234

119. Velasco E, Goto K, Sugawara D, Nishimura Y (2019a) A Scheme Proposal for an Effective Selection of Survey Sites in Paleotsunami Research, Hachinohe, Aomori Prefecture, Japan. In: Proceedings of CWMD International Conference 2019. Kumamoto University, Kumamoto, Japan, pp 1-10

120. Velasco E, Goto K, Sugawara D, Nishimura Y (2019b) A Scheme Proposal for an Effective Selection of Survey Sites in Paleotsunami Research, Hachinohe, Aomori Prefecture, Japan. In: Proceedings of CWMD International Conference. Kumamoto University, Kumamoto, Japan, pp 189-198

121. Watanabe M, Bricker JD, Goto K, Imamura F (2017) Factors responsible for the limited inland extent of sand deposits on Leyte Island during 2013 Typhoon Haiyan. J Geophys Res Ocean 122(4):2795-2812. https://doi.org/10.1002/2013JC009262.Received

122. Watanabe M, Goto K, Bricker JD, Imamura F (2018) Are inundation limit and maximum extent of sand useful for differentiating tsunamis and storms? An example from sediment transport simulations on the Sendai Plain, Japan. Sediment Geol 364:204-216. https://doi.org/10.1016/j.sedgeo.2017.12.026

123. Watanabe T, Ohtsuka T, Tuji A (2005) Picture Book and Ecology of the Freshwater. Diatoms

124. Witkowski A, Lange-Bertalot $H$, Metzeltin D (2000) Diatom flora of marine coasts 1. In: Iconographia Diatomologica. Koeltz Scientific Books, Königstein

125. Yoshii T, Tanaka S, Matsuyama M (2017) Tsunami deposits in a super-large wave flume. Mar Geol 391. https://doi.org/10.1016/j.margeo.2017.07.020

\section{Tables}

Due to technical limitations, table 1 is only available as a download in the Supplemental Files section.

\section{Figures}

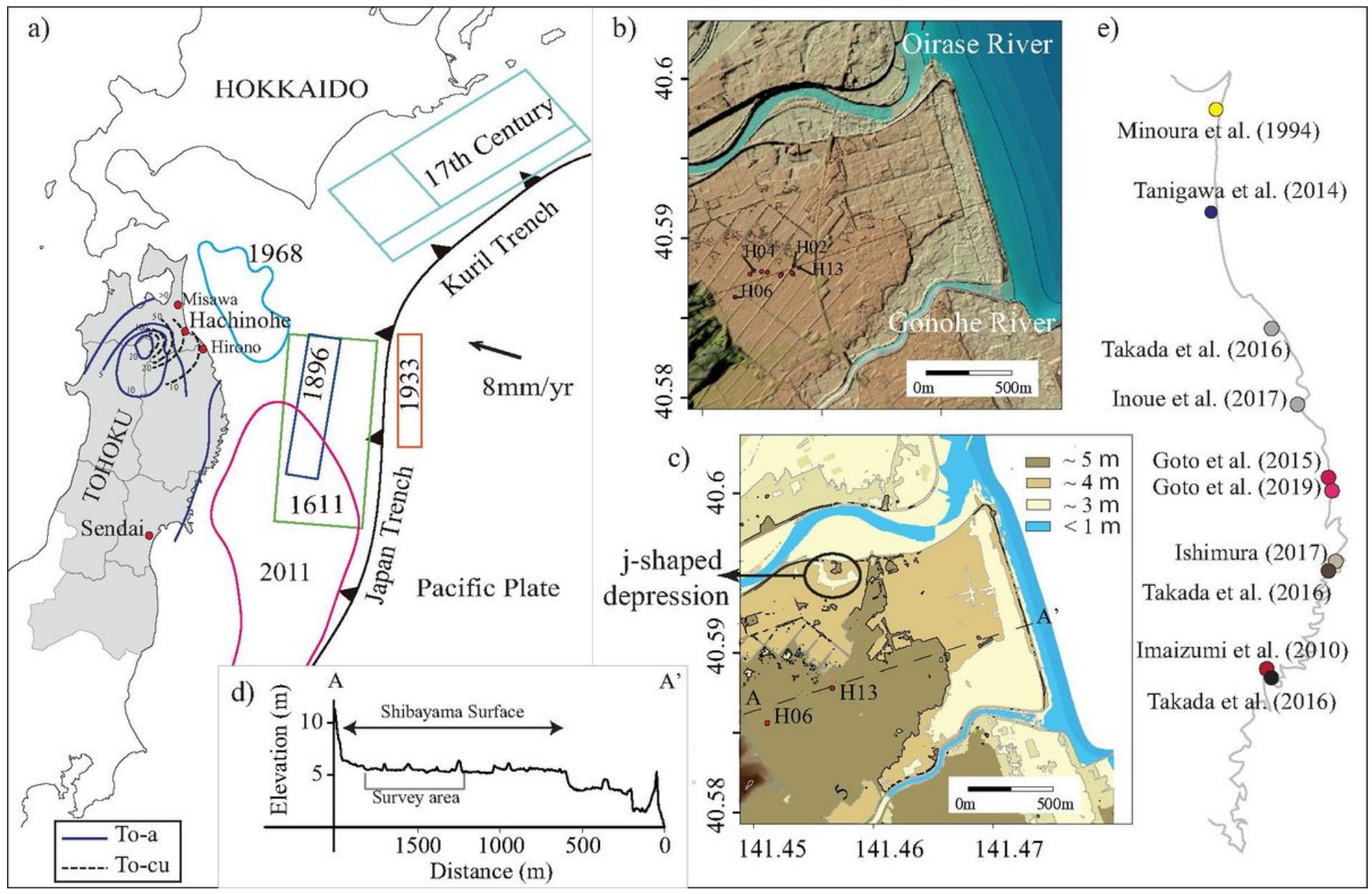

Figure 1 
Map of the study area. a) Location of the modeled rupture areas for the tsunamigenic earthquakes of 17th century, 1611, 1896, 1933, 1968, and 2011. (Hatori 1975; Tanioka and Satake 1996; Nagai et al. 2001; Ozawa et al. 2011; loki and Tanioka 2016; Uchida et al. 2016); To-a and To-cu correspond to the isopachs of the respective tephra layers (Machida and Arai 2003). b) Digital elevation model of the study area. c) Topographic map of the study area. Colored areas evidenced two levels of uplifted marine terraces: $5 \mathrm{~m}$ (Shibayama surface), $4 \mathrm{~m}$ and $3 \mathrm{~m}$. d) Cross section of the elevation model along the study area, from the $A$ to $A^{\prime}$.

a)

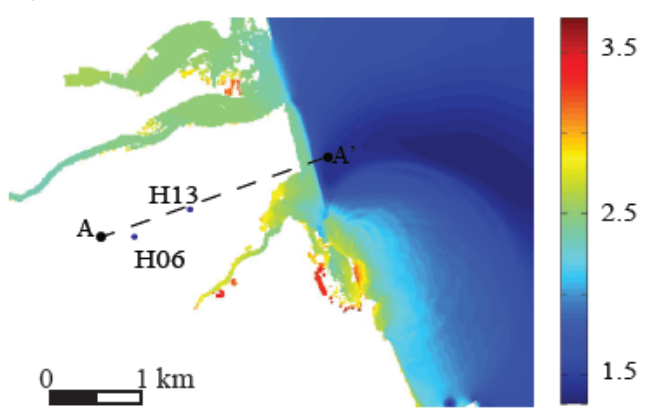

b)

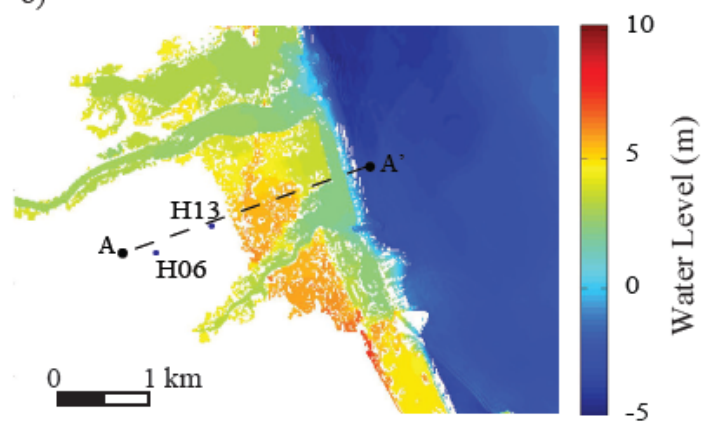

c)

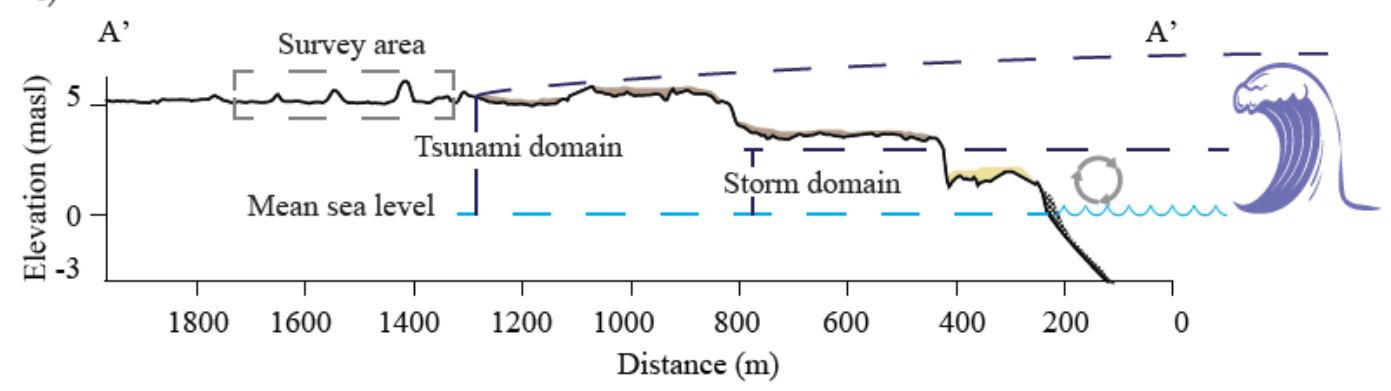

\begin{tabular}{|llll|}
\hline Expected tsunami deposit & Main sediment source zone \\
Expected storm deposit & $\bigcirc$ & Storm reworking zone \\
\hline
\end{tabular}

Figure 2

Maximum calculated inundation areas for storm and tsunami events for the survey site. (modified after Velasco et al., 2019). a) Maximum calculated inundation by storm surge. b) Maximum calculated inundation by tsunami surge. c) Schematic model comparing storm and tsunami inundation capacity.

(a)

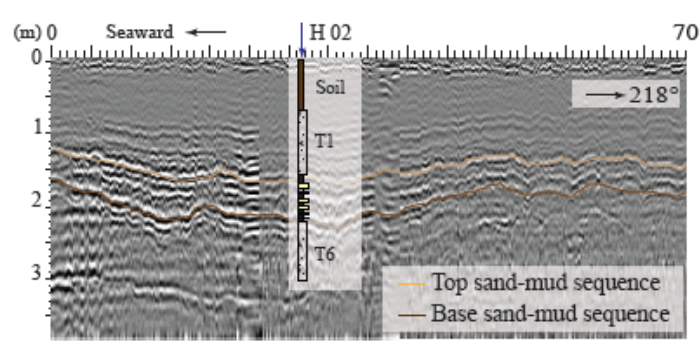

(b)

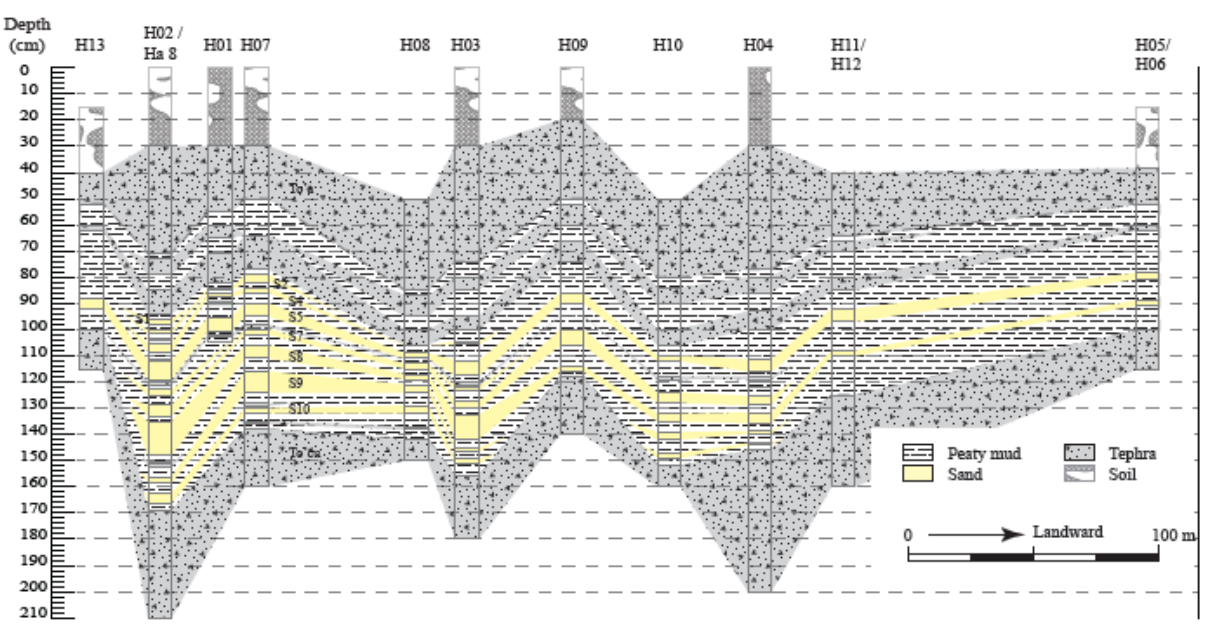

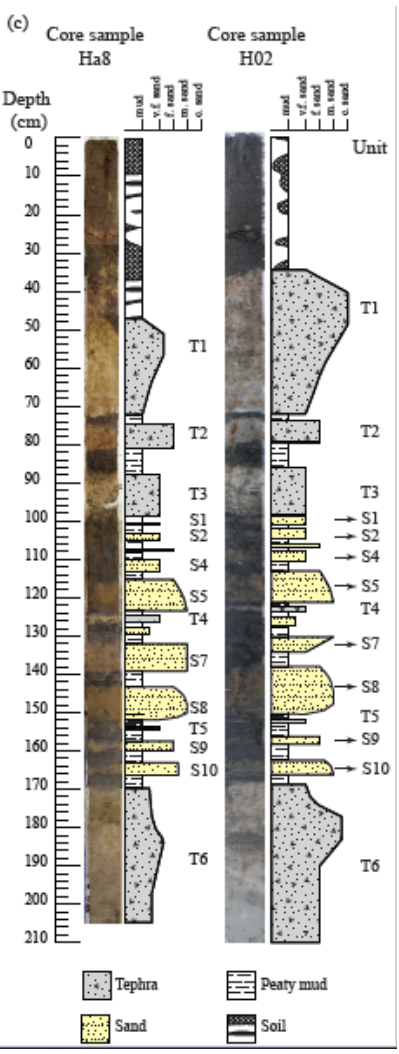


Figure 3

(a) Location on the GPR profile core sample H02. (b) Relative position of horizontal core sample and sand events correlation, based on sedimentary features and stratigraphic relationships. For lateral correlation of the sand layers S1 to S10, see the discussion section in the body text. (c) Stratigraphic column of core samples $\mathrm{Ha} 8$ and $\mathrm{H} 02$, separated laterally by $\sim 1 \mathrm{~m}$.

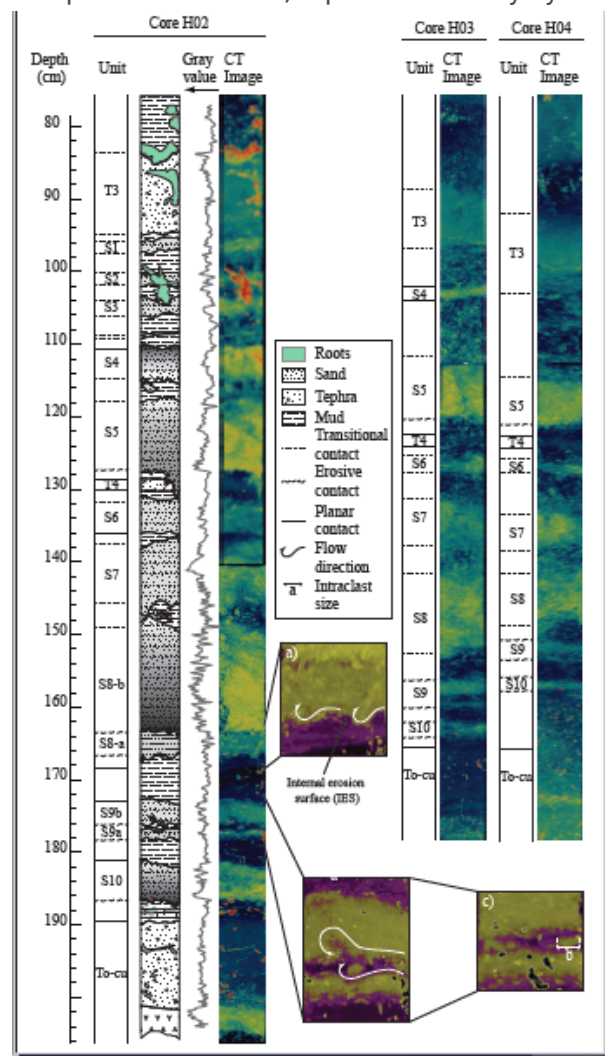

\section{Figure 4}

$\mathrm{CT}$ image interpretation for the core sample $\mathrm{H02}, \mathrm{HO}$, and $\mathrm{H} 04$. From left to right: depth, core $\mathrm{H} 02$ : stratigraphic column, sedimentary texture and structures, gray value, and $\mathrm{CT}$ image; cores $\mathrm{HO} 3$ and $\mathrm{H} 04$ : stratigraphic column and $\mathrm{CT}$ images. Gray tone gradient depicts sediment grading. a, b, and c correspond to closer looks showing flow sedimentary structures and the size of a rip-up clast at S8 and S9.

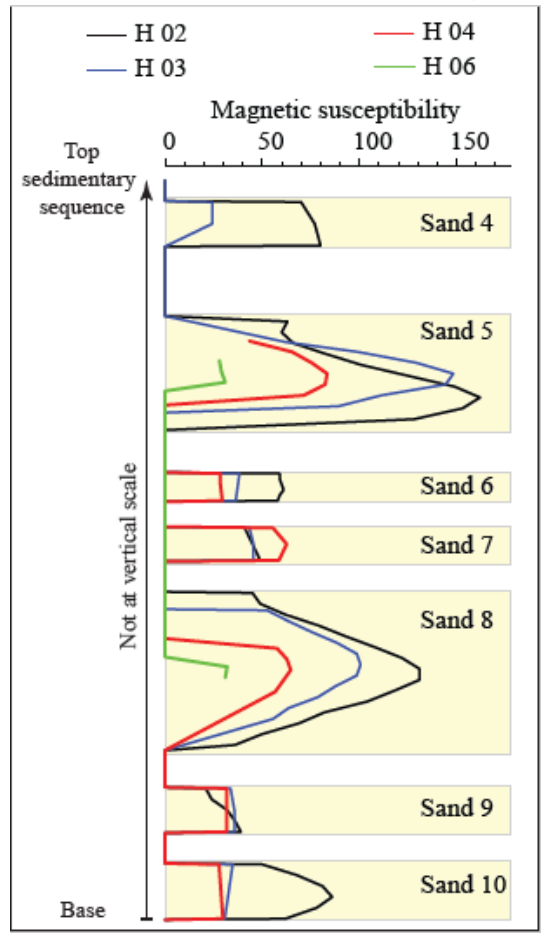

Figure 5 
Magnetic susceptibility landward change along with the core samples $\mathrm{H} 02, \mathrm{H} 03, \mathrm{H} 04$, and $\mathrm{H} 06$. Note that it is a graphic representation of the MS intensity, and the thickness of the sand layers is not at scale.

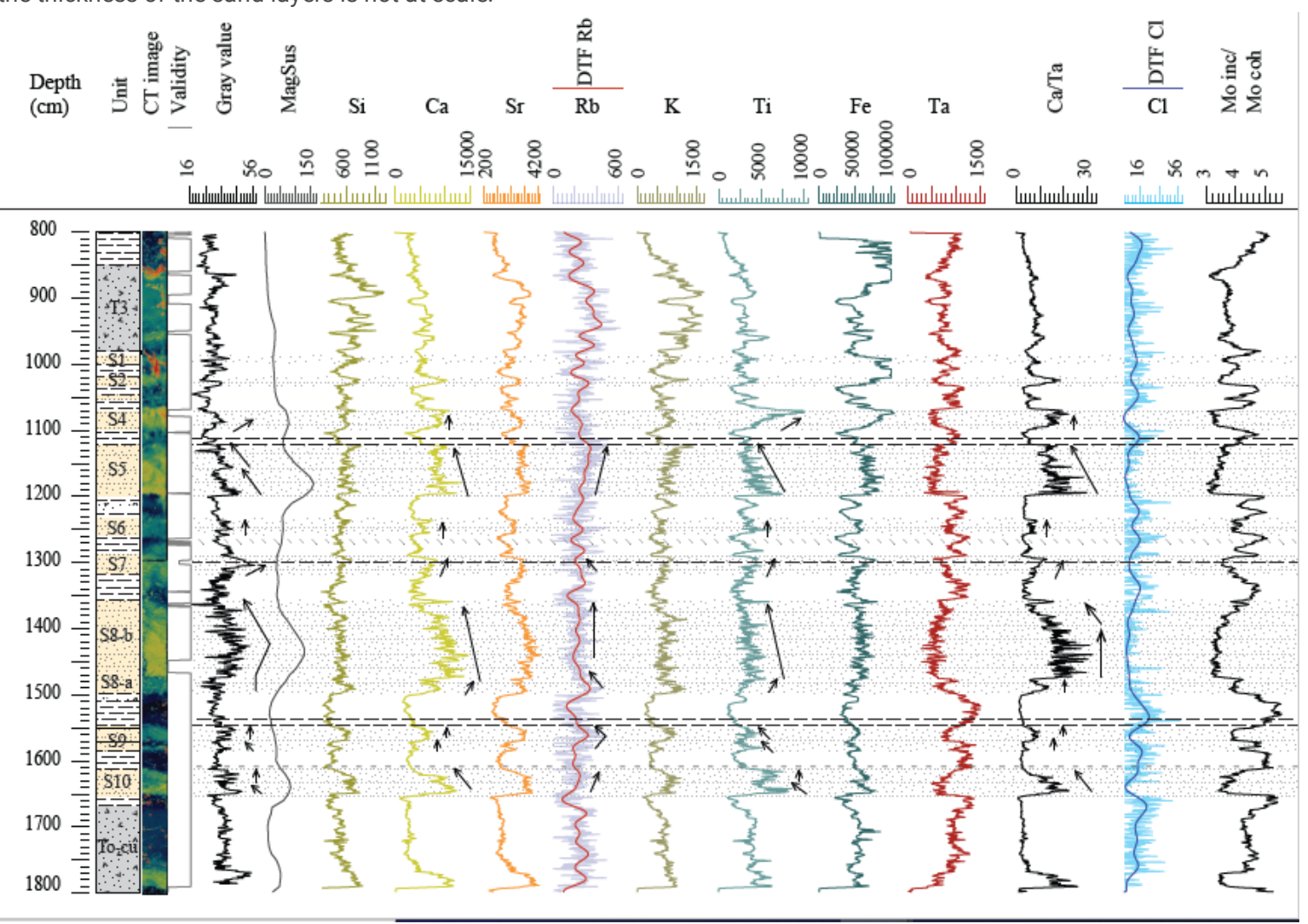

\section{Figure 6}

Log pane of the core sample H02. Log distribution: depth, stratigraphic units, CT image, validity, gray value profile, magnetic susceptibility, and micro X-ray fluorescence elements result ( $\mathrm{Si}, \mathrm{Ca}, \mathrm{Sr}, \mathrm{Rb}, \mathrm{K}, \mathrm{Ti}, \mathrm{Fe}, \mathrm{Ta}, \mathrm{Ca} / \mathrm{Ta}, \mathrm{Cl}$, and Inc/Coh) vs depth. DTF: Discrete Fourier transform. Black arrows indicate trend changes in pattern intensity.

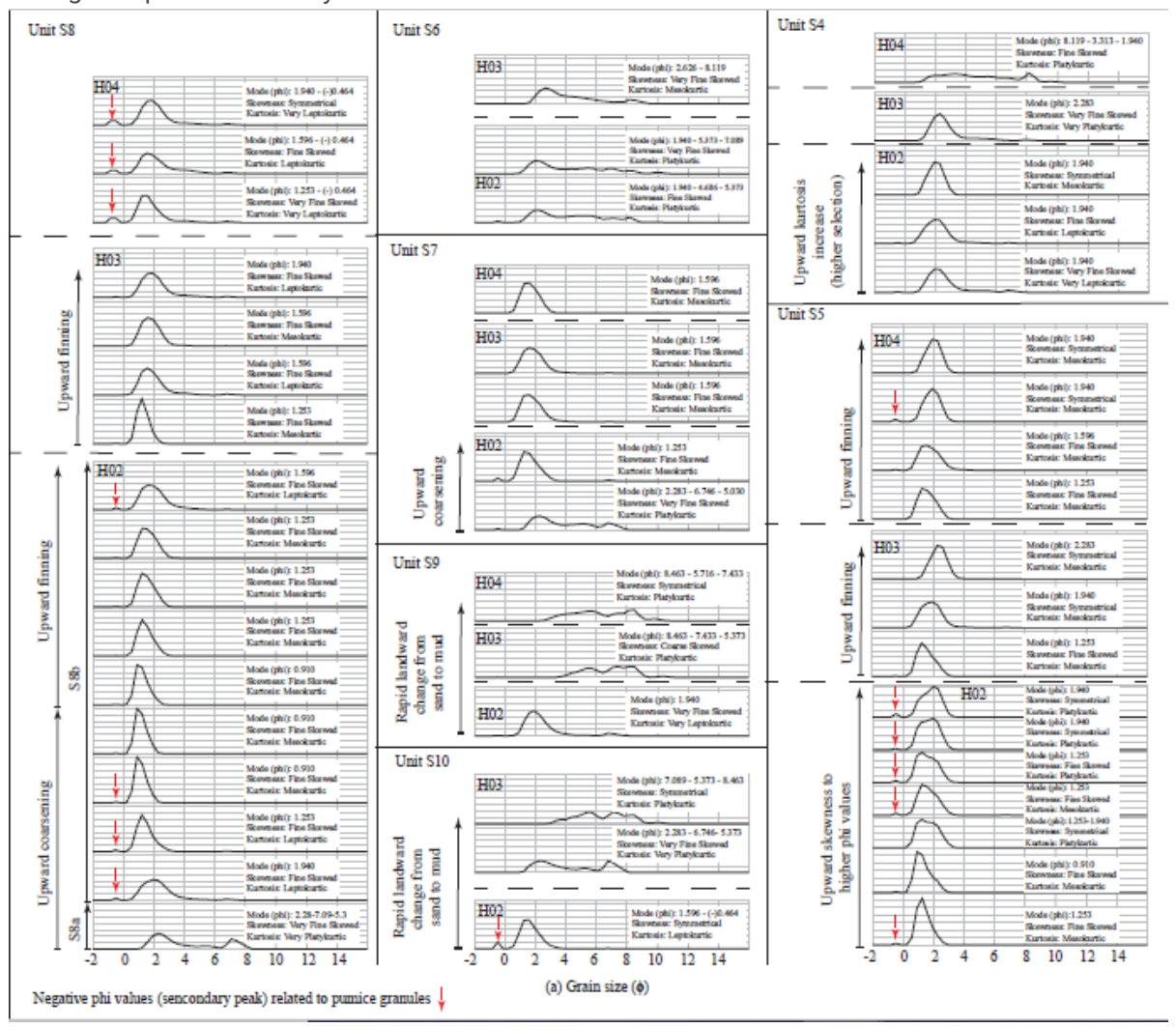




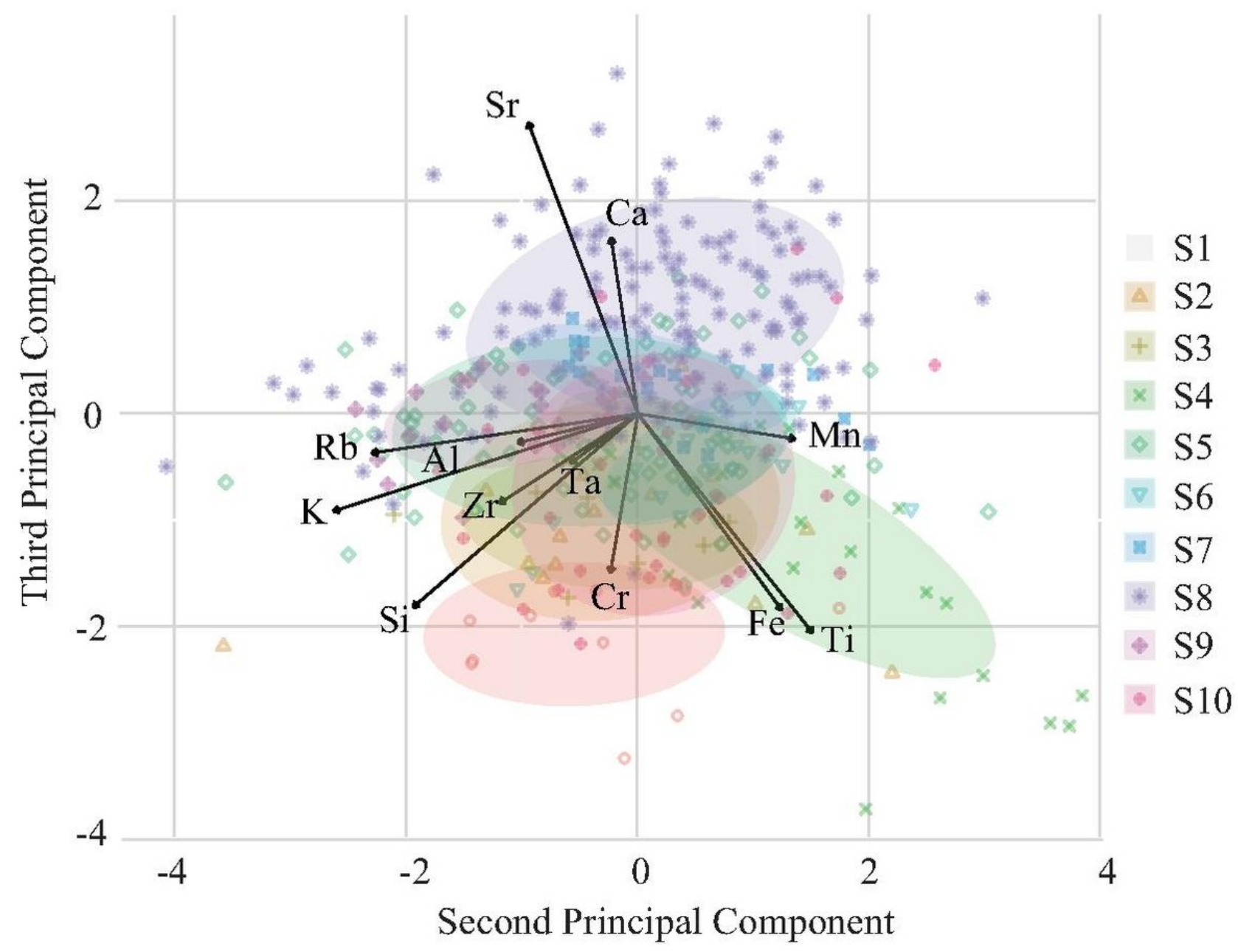

Figure 8

Principal component analysis results for ITRAX results in core $\mathrm{H} 02$.

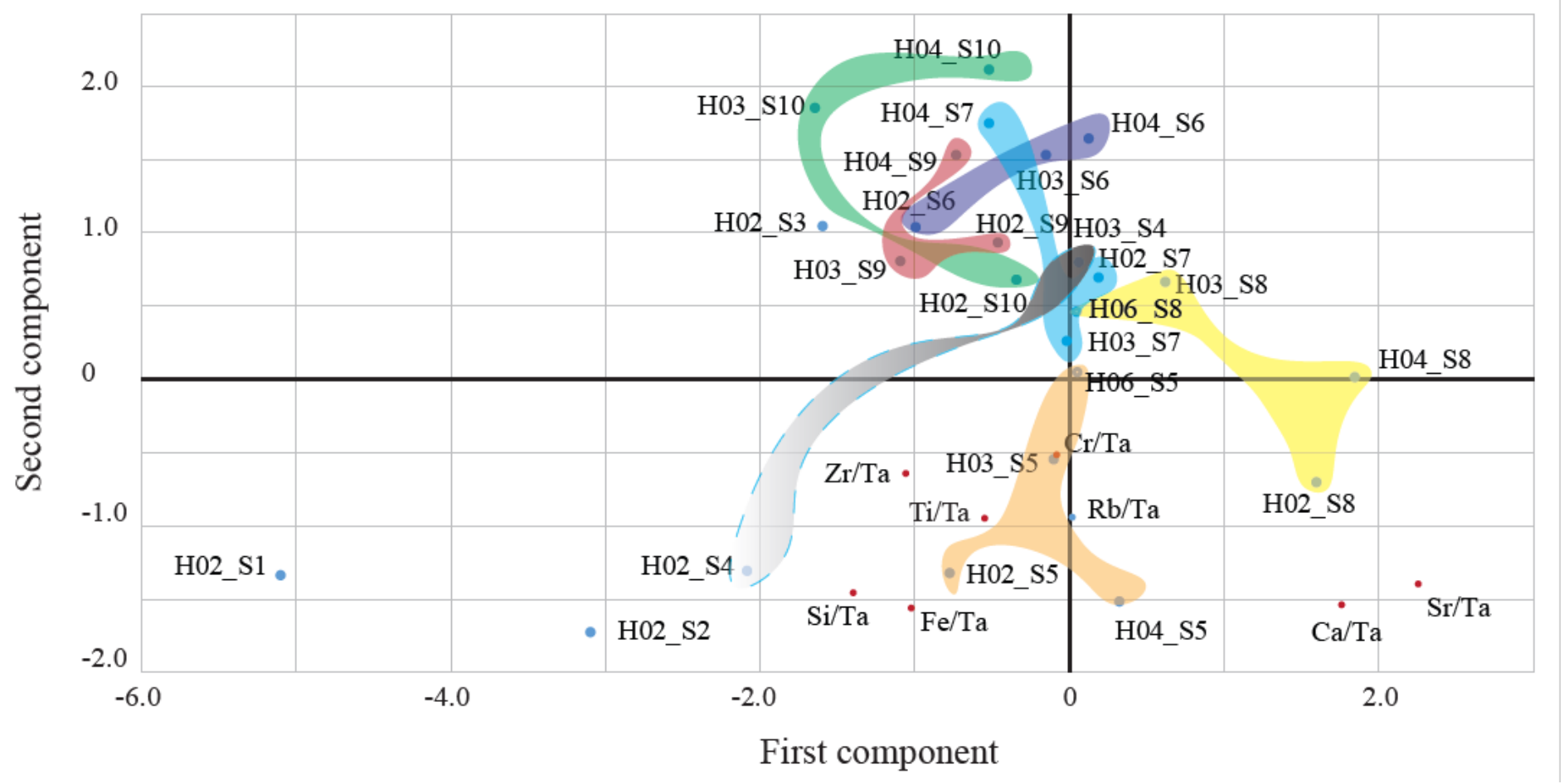

Page $24 / 28$ 


\section{Figure 9}

Linear discriminant analysis results for ITRAX results in core H02. Elements used for discrimination: $\mathrm{Sr}, \mathrm{Ca}, \mathrm{Rb}, \mathrm{Cr}, \mathrm{Zr}$, Ti, Fe, and $\mathrm{Si}$, normalized by Ta. Every point corresponds to the component value for every sand layer in every core. Color shades represent correlations among sand layers.

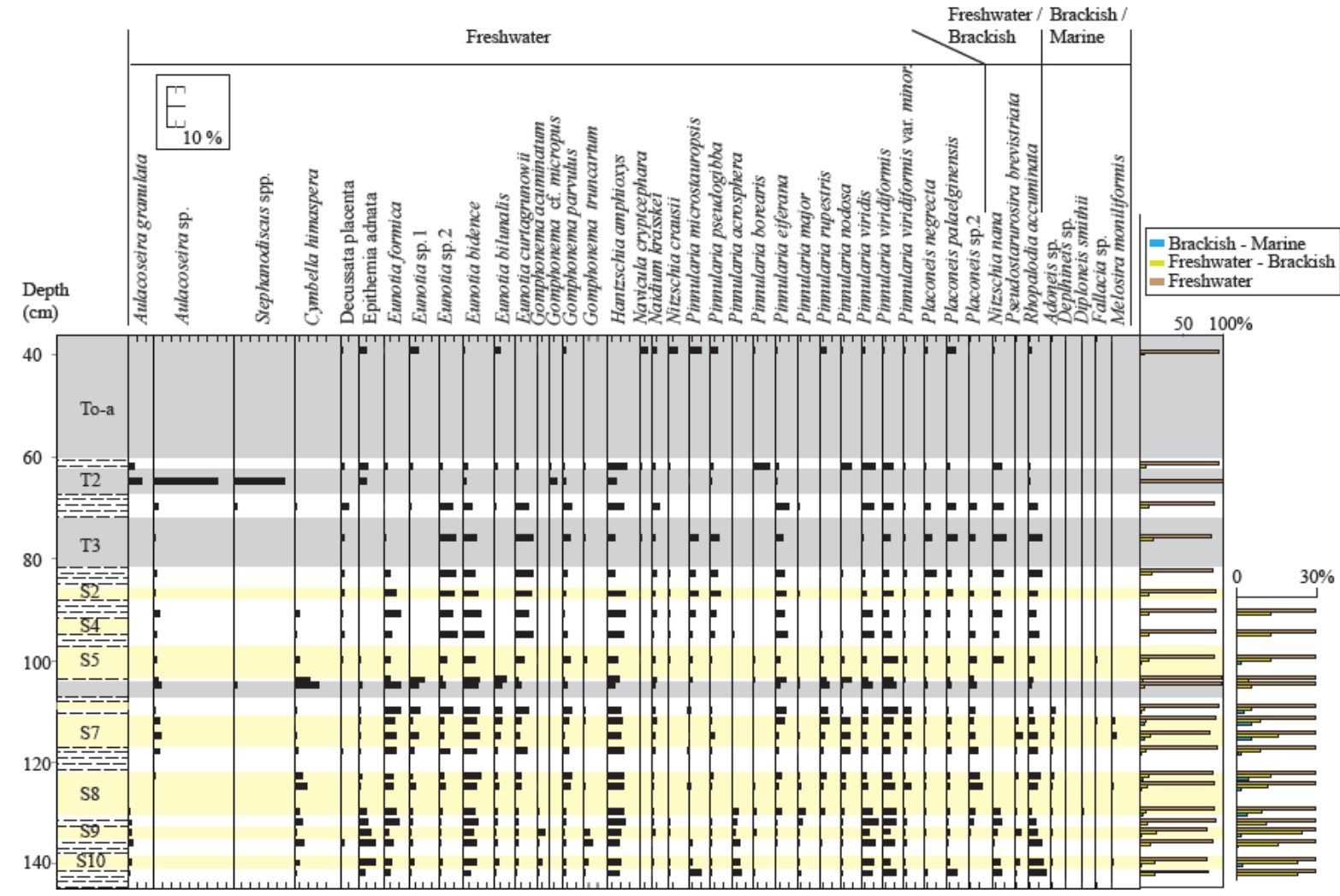

\section{Figure 10}

Diatom analysis result for the core sample Ha 8. In the horizontal axis are described the diatom species found along with the sediment core: freshwater, freshwater-brackish, and brackish-marine environments. On the right side, diatom-origin proportion is described as a percentage. A close view depicts the presence of marine species (from 0 to $30 \%$ ).

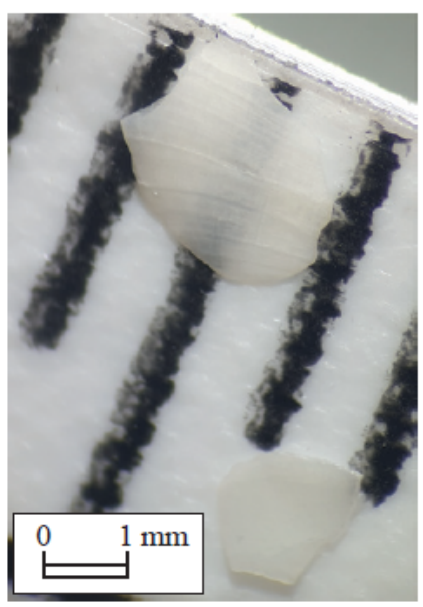

Figure 11

Shell fragment recovered from S5. 


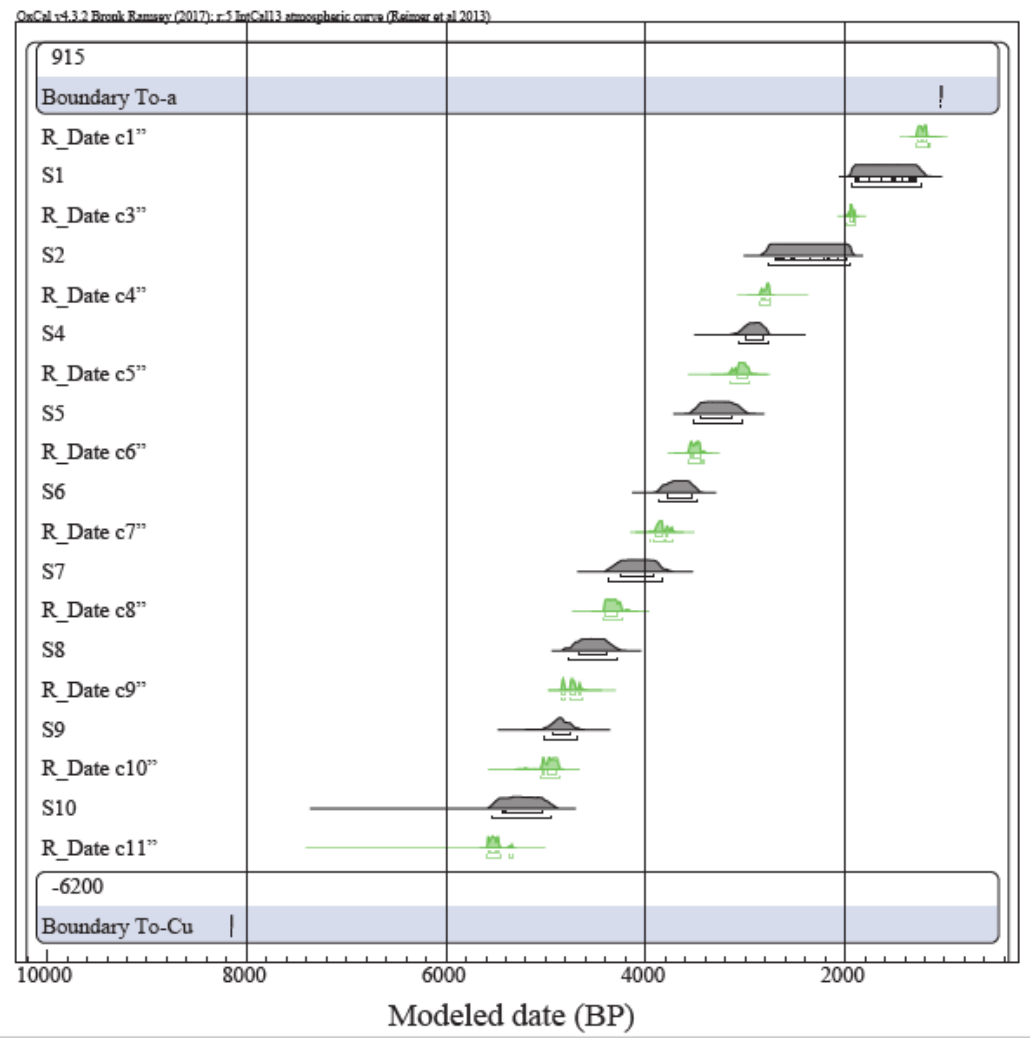

\section{Figure 12}

Calibrated 14C dating results and modeled dates for samples obtained from core sample Ha8. Modeled dates are shown with a probability of $95 \%$ (2б). R_Date curves correspond to each calibrated sample result. Gray curves correspond to calculated deposition ages. Sequence model is bounded by To-a and To-cu tephra events.

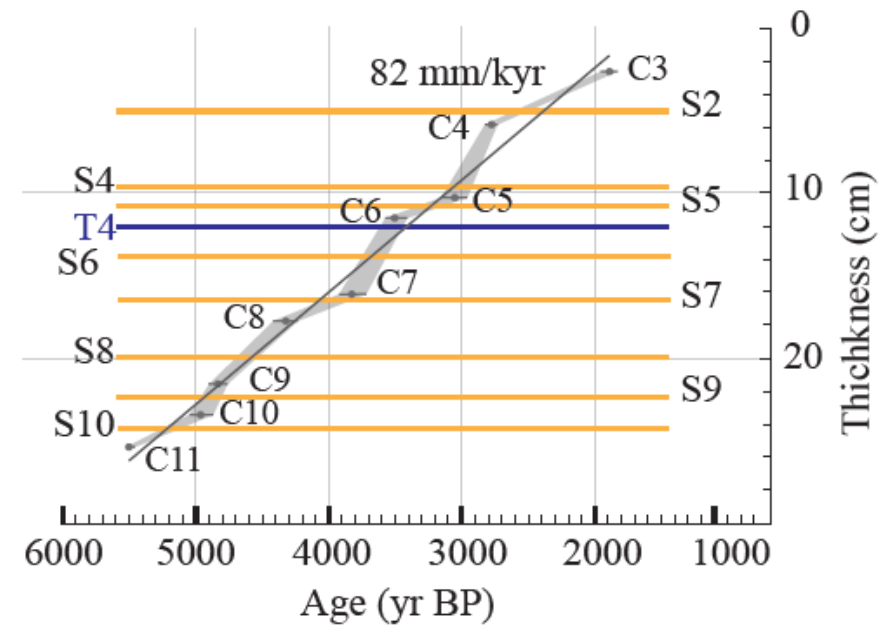

Figure 13

Sedimentation rate for the study area from $5500 \mathrm{yr}$. BP to $1000 \mathrm{yr}$. BP. Time spam was inferred from dating results. C values correspond to dating samples. 


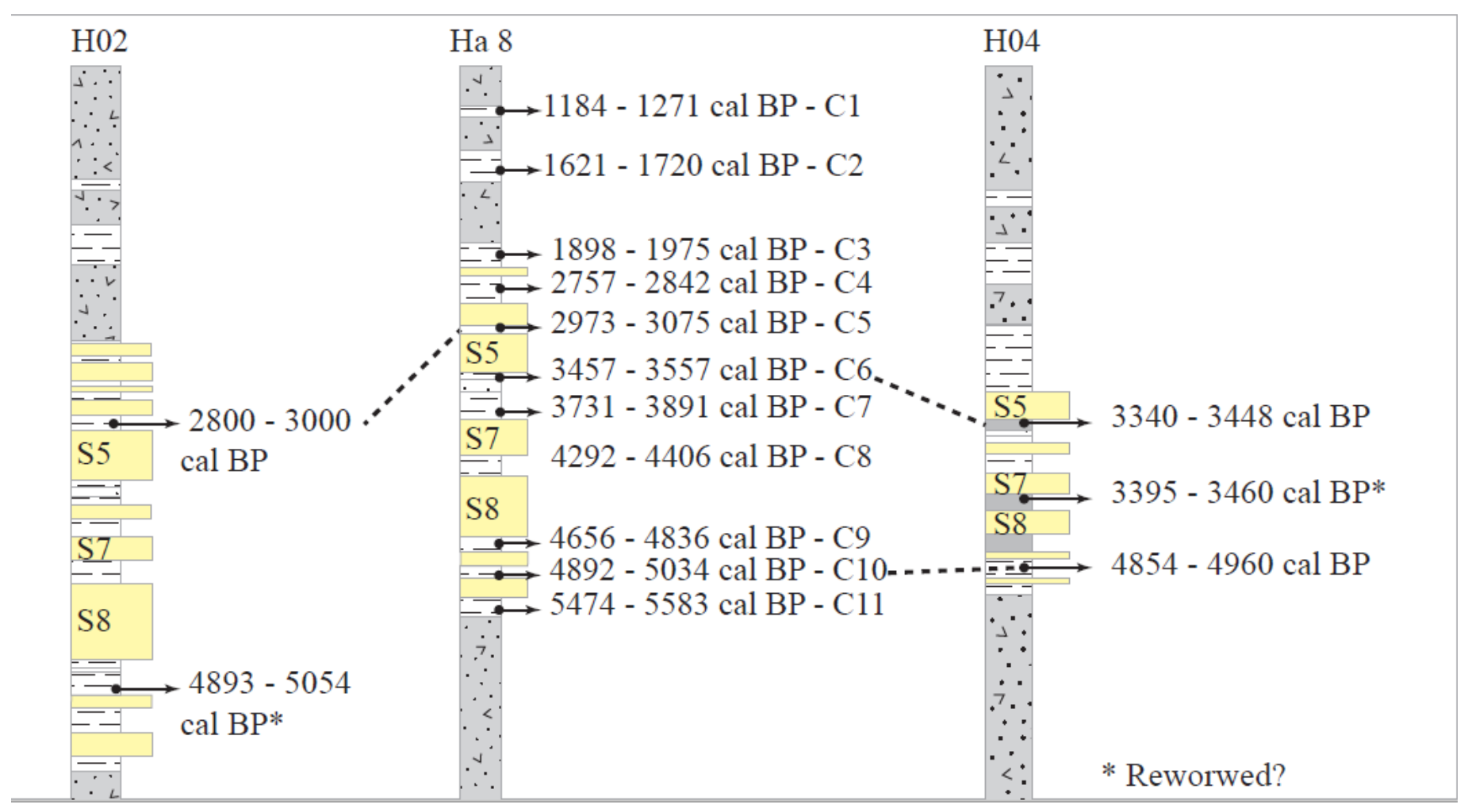

Figure 14

Carbon dating results and ages correlation among core samples $\mathrm{H02}, \mathrm{Ha} 8$, and $\mathrm{H} 04$. C\# notation corresponds to the sample number described in the dating model on Fig. 12.

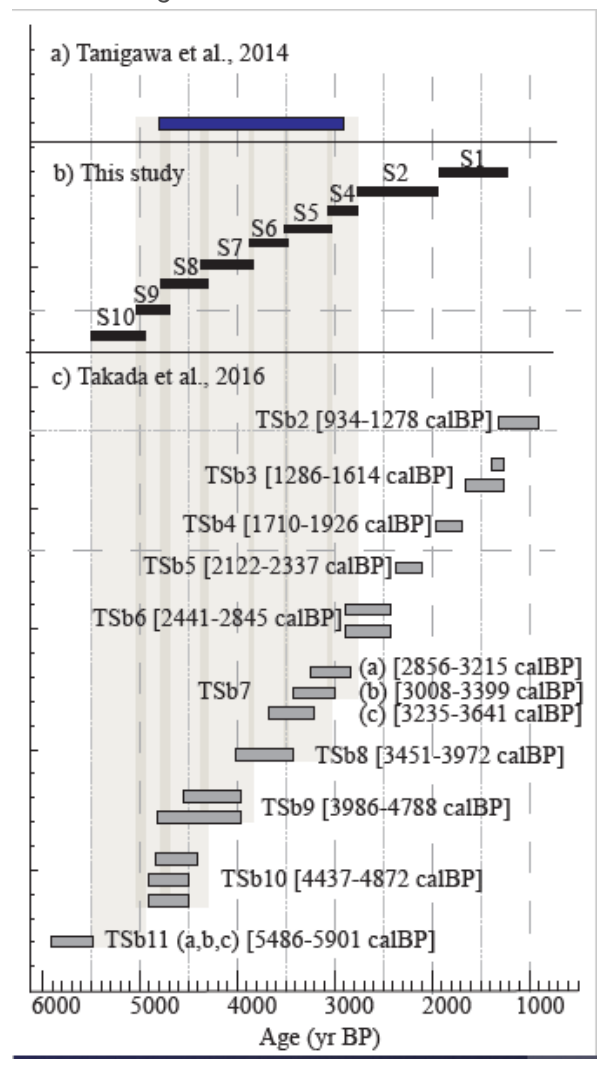

\section{Figure 15}

Chronological correlation with previous studies conducted close to Hachinohe area. a) Tanigawa et al., 2014 in Misawa, northern Aomori; b) This study; c) Takada et al., 2016 in Harashinai site, TSd stands for tsunami sand. 
a)

\section{Seaward $\longleftarrow$ H 04}

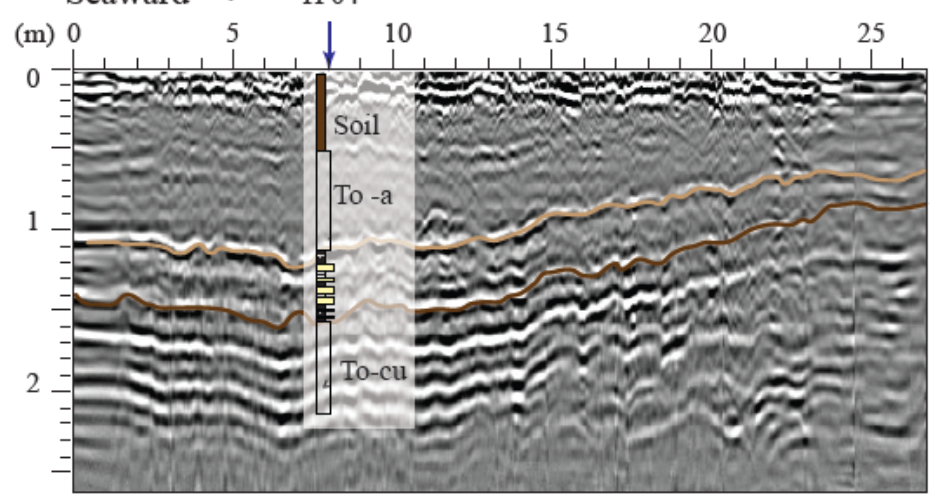

Top sand-mud sequence

Base sand-mud sequence b)

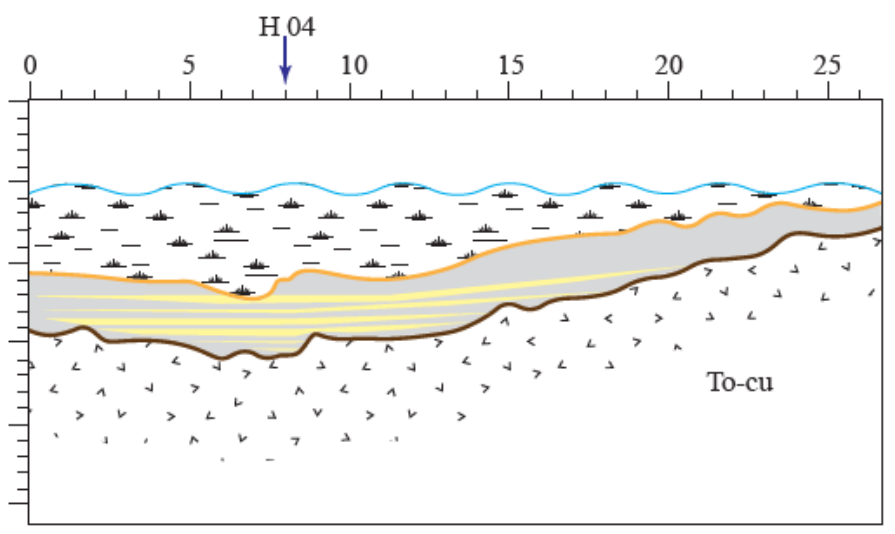

Tsunami sand deposit Peaty mud
Marsh environment Landward

\section{Figure 16}

Paleosedimentary environment for the base of the peaty-mud sequence. a) Ground penetrating radar image obtained around H04 sampling area. Strong reflectors display the top and base of the sand/peaty-mud sequence. b) Interpreted sedimentary environment from diatom results, sedimentary characteristics, and GPR imagery.

\section{Supplementary Files}

This is a list of supplementary files associated with this preprint. Click to download.

- Graphicalabstractimage.pdf

- Appendix1.docx

- Appendix2.pdf

- Appendix3.pdf

- Appendix4.pdf

- Appendix5.pdf

- Table1.xlsx 